\title{
Msx1 haploinsufficiency modifies the Pax9-deficient cardiovascular phenotype
}

\author{
Ramada R. Khasawneh 1,8, Ralf Kist ${ }^{1,2}$, Rachel Queen ${ }^{3}$, Rafiqul Hussain ${ }^{4}$, Jonathan Coxhead ${ }^{4}$,
} Jürgen E. Schneider ${ }^{5}$, Timothy J. Mohun ${ }^{6}$, Stéphane Zaffran ${ }^{7}$, Heiko Peters ${ }^{1}$, Helen M. Phillips ${ }^{1}$ and Simon D. Bamforth ${ }^{*}$

\begin{abstract}
Background: Successful embryogenesis relies on the coordinated interaction between genes and tissues. The transcription factors Pax9 and Ms 1 genetically interact during mouse craniofacial morphogenesis, and mice deficient for either gene display abnormal tooth and palate development. Pax9 is expressed specifically in the pharyngeal endoderm at mid-embryogenesis, and mice deficient for Pax9 on a C57BI/6 genetic background also have cardiovascular defects affecting the outflow tract and aortic arch arteries giving double-outlet right ventricle, absent common carotid arteries and interruption of the aortic arch.

Results: In this study we have investigated both the effect of a different genetic background and MsX1 haploinsufficiency on the presentation of the Pax9-deficient cardiovascular phenotype. Compared to mice on a C57BI/6 background, congenic CD1-Pax $9^{-/-}$mice displayed a significantly reduced incidence of outflow tract defects but aortic arch defects were unchanged. Pax $9^{-/-}$mice with Ms $x 1$ haploinsufficiency, however, have a reduced incidence of interrupted aortic arch, but more cases with cervical origins of the right subclavian artery and aortic arch, than seen in $\mathrm{PaX}^{-/-}$mice. This alteration in arch artery defects was accompanied by a rescue in third pharyngeal arch neural crest cell migration and smooth muscle cell coverage of the third pharyngeal arch arteries. Although this change in phenotype could theoretically be compatible with post-natal survival, using tissue-specific inactivation of Pax9 to maintain correct palate development whilst inducing the cardiovascular defects was unable to prevent postnatal death in the mutant mice. Hyoid bone and thyroid cartilage formation were abnormal in $\mathrm{Pax}^{-/-}$mice.
\end{abstract}

Conclusions: MsX1 haploinsufficiency mitigates the arch artery defects in $\mathrm{Pax}^{-/-}$mice, potentially by maintaining the survival of the 3rd arch artery through unimpaired migration of neural crest cells to the third pharyngeal arches. With the neural crest cell derived hyoid bone and thyroid cartilage also being defective in $\mathrm{Pax}{ }^{-/-}$mice, we speculate that the pharyngeal endoderm is a key signalling centre that impacts on neural crest cell behaviour highlighting the ability of cells in different tissues to act synergistically or antagonistically during embryo development.

Keywords: Cardiovascular development, Pharyngeal endoderm, Pax9, Msx1, Neural crest

*Correspondence: simon.bamforth@newcastle.ac.uk

${ }^{1}$ Newcastle University Biosciences Institute, Centre for Life,

Newcastle NE1 3BZ, UK

Full list of author information is available at the end of the article

\section{Background}

Morphogenetic processes rely on tightly regulated gene expression patterns and interactions at critical time points during development. Certain genes may also be utilised at different time points and in different tissues for formation of distinct structures [1]. For example, the transcription factor $\operatorname{Pax} 9$ is required for palate, tooth, taste papillae, thymus, skeletal and cardiovascular 
development [2-5]. Pax9 is specifically expressed in the pharyngeal endoderm at mid-embryogenesis with wider expression in the craniofacial region and skeletal precursors later in development [6, 7]. Mice lacking $\operatorname{Pax} 9$ die in the neonatal period with cleft palate, tooth agenesis [4] and cardiovascular defects which are the most likely cause of death [2,3]. Cleft palate is among the most common human birth defects [8], and congenital cardiac anomalies are one of the most frequent disorders associated with cleft lip and palate [9]. Mouse mutants with complete cleft palate die within $24 \mathrm{~h}$ of birth without having fed, most likely due to a combination of factors such as the inability to suckle and respiratory distress [10].

Shared specific phenotypes in mutant mouse models can be indicators of a genetic interaction between genes (epistasis) suggesting they are involved in the same gene regulatory network [11]. Pax9 and Msx1, for example, are co-expressed during craniofacial development, and mice deficient for Msx 1 show similar phenotypes to Pax9-deficient mice by exhibiting cleft palate and abnormalities of craniofacial and tooth development $[4,12]$. Protein-protein interactions occur between Pax9 and Msx1 in vitro [13] and Pax9 and Msx1 interact synergistically in vivo throughout lower incisor development and affect multiple signalling pathways that influence incisor size and asymmetry [14]. Whereas cleft lip formation is incompletely penetrant in $\operatorname{Pax} 9 ; M s \times 1$ double homozygous mutants, lower incisors are missing in Pax9;Msx1 double heterozygotes indicating variable gene dosage requirements in different tissues $[14,15]$. Pax9 is able to directly regulate Msx1 expression and interact with Msx1 at the protein level to enhance its ability to transactivate Bmp4 expression during tooth development [16].

Pax9-deficient mice have cardiovascular defects affecting the outflow tract and aortic arch arteries, with double outlet right ventricle (DORV), interrupted aortic arch type B (IAA-B), aberrant right subclavian artery (A-RSA) and absent common carotid arteries observed at a high penetrance [3]. These defects are thought to derive from altered signalling processes originating from the pharyngeal endoderm, from a yet to be identified mechanism, but could potentially involve a pathway linking to neural crest cell (NCC) migration or differentiation [3]. A pathway that shares $\operatorname{Pax} 9$ and $M s \times 1$ could be a possibility as the two proteins are known to interact and $M s x 1$ is expressed in migrating NCC in the pharyngeal arches at E9.5, and these cells differentiate and contribute to the smooth muscle cells (SMC) coating the great arteries [17, 18]. Although Msx1-null mice have normal cardiovascular development, $M s x 1 ; M s x 2$ double homozygous mutant mice die in utero with neural crest, outflow tract and atrioventricular valve defects $[19,20]$. Mutation of either
PAX9 or MSX1 has been implicated in human congenital heart defects [21-26].

Genetic modifiers in different strain backgrounds of mouse models of disease play an important role in phenotype presentation [27], including cardiovascular defects [28, 29]. For example, Msx1-deficient mice die more rapidly on a $\mathrm{C} 57 \mathrm{Bl} / 6$ background compared to a mixed genetic background [30] and Pax9;Msx1 homozygous mutants present with a cleft lip on a mixed background, but this is completely suppressed on a CD1 background [14].

In this study we had two objectives: to investigate the Pax9-deficient cardiovascular phenotype on a different genetic background to $\mathrm{C} 57 \mathrm{Bl} / 6$, and to identify if there was a genetic interaction between $\operatorname{Pax} 9$ and $M s x 1$ in cardiovascular development.

\section{Results}

To investigate if the fully penetrant cardiovascular defects seen in mice on a congenic $\mathrm{C} 57 \mathrm{Bl} / 6$ genetic background (B6-Pax9) were recapitulated on a different genetic background we examined Pax9-deficient mice (hereafter referred to as $\mathrm{Pax}^{-/-}$) which had been backcrossed in excess of 20 generations on an outbred CD1 genetic background (CD1-Pax9). These congenic CD1-Pax $9^{+/-}$ mice were subsequently intercrossed to produce CD1$\mathrm{Pax}^{9^{-/-}}$embryos at E15.5 for analysis by MRI, $\mu \mathrm{CT}$ and histology $(n=25)$. A further 22 neonates were collected on the day of birth and analysed for aortic arch artery defects by dissection and direct visualisation. From a subset of these neonates $(n=12)$, the heart was removed and further examined for outflow tract and intracardiac defects by histology (Table 1). This analysis revealed that all CD1-Pax $9^{-/}$embryos and neonates presented with a cleft palate, a severely hypoplastic thymus absent from the normal position, and a pre-axial digit duplication (Fig. 1A-H) as previously reported [4]. Surprisingly, CD1-Pax $9^{-/-}$mice had a significantly lower incidence of DORV compared to our published data for B6- $\mathrm{Pax} 9^{-/-}$ neonates and embryos [3] ( $\mathrm{n}=24 ; 16 \%$ vs. $79 \%, p<0.001$; Fig. 2E; Table 1), although a very similar incidence of VSD and arch artery defects (IAA and A-RSA) was observed (Figs. 1I-Q; 2F, G; Table 1). Bicuspid aortic valve, however, was not observed. These data demonstrate that a change in genetic background affects the penetrance of the outflow tract defects in CD1-Pax $9^{-/-}$mice, although the incidence of arch artery defects was consistent.

Pax9 and Msx 1 are known to be co-expressed and interact in craniofacial development [14]. To explore if $\operatorname{Pax} 9$ and $M s \times 1$ are also co-expressed in the pharyngeal arches at mid-embryogenesis we used lineage tracing and single cell analysis. To visualise specific Pax9 and $M s x 1$ expression within the pharyngeal arches at 
Table 1 Cardiovascular defects in Pax9 and Pax9;Msx1 mutant E15.5 embryos and neonates

\begin{tabular}{|c|c|c|c|c|c|c|c|}
\hline $\begin{array}{l}\text { Genetic background- } \\
\text { genotype }\end{array}$ & $\mathrm{n}$ & VSD & DORV + IVC & cAo & $\mathrm{IAA} \pm \mathrm{A}-\mathrm{RSA}$ & $A-R S A(w / o ~ I A A)$ & Absent CC \\
\hline B6-Pax $9^{-/-a}$ & 24 & $3 / 19(16 \%)$ & 15/19 (79\%) & 0 & $22 / 24(92 \%)$ & $2 / 24(8 \%)$ & $17 / 24(71 \%)$ \\
\hline CD1-Pax $9^{-/-b}$ & 47 & $10 / 37(27 \%)$ & $6 / 37(16 \%)^{* * *}$ & $2 / 47(4 \%)$ & $41 / 47(87 \%)$ & $6 / 47(13 \%)$ & $27 / 47(57 \%)$ \\
\hline $\mathrm{CD} 1-\mathrm{Pax}^{-/-} ; \mathrm{Ms} \times 1^{+/-c}$ & 38 & $2 / 29(7 \%)$ & $1 / 29(3 \%)$ & $9 / 38(24 \%)^{*}$ & $11 / 38(29 \%)^{* * *}$ & $19 / 38(50 \%)^{* * *}$ & $9 / 38(24 \%)^{*}$ \\
\hline CD1-Pax9 $9^{-/-} ; M s \times 1^{-/-d}$ & 7 & 0 & $1 / 7(14 \%)$ & 0 & 2/7 (29\%) & 0 & 0 \\
\hline
\end{tabular}

Ao, aorta; A-RSA, aberrant right subclavian artery; DORV + IVC, double outlet right ventricle with interventricular communication; IAA, interrupted aortic arch; VSD, perimembranous ventricular septal defect

${ }^{* * *} p<0.001 ;{ }^{*} p<0.05$ (Fisher's exact test for associations)

${ }^{a}$ Data for $\mathrm{Pax}^{-/-}$mice on a C57BI/6J (B6) genetic background have been published [3]. Aortic arch artery defects for neonates $(n=5)$ and E14.5-15.5 embryos ( $\left.n=19\right)$ are pooled. VSD and DORV + IVC data from embryos only. A-RSA refers to a retro-oesophageal, cervical origin or isolated right subclavian artery. Absent common carotid artery (CC), resulting in the internal and external carotid arteries arising directly from the main aortic vessels, either unilaterally or bilaterally. All embryos had cleft palate and an absent thymus, and all embryos except $\operatorname{Pax}^{-1-} ; M s \times 1^{-/-}$had a pre-axial digit duplication

${ }^{\mathrm{b}}$ For $\mathrm{CD} 1-\mathrm{Pax}^{-/-}$mice, aortic arch artery defects for neonates $(\mathrm{n}=22)$ and E15.5 embryos $(\mathrm{n}=25)$ are pooled. VSD and DORV + IVC data are from all embryos and $\mathrm{n}=12$ neonates (by histology)

${ }^{\mathrm{C}}$ For CD1-Pax9 ${ }^{-/-} ; \mathrm{Msx}^{+/-}$mice, aortic arch artery defects for neonates $(\mathrm{n}=20)$ and $\mathrm{E} 15.5$ embryos $(\mathrm{n}=18)$ are pooled. VSD and DORV + IVC data from all embryos and $\mathrm{n}=11$ neonates (by histology)

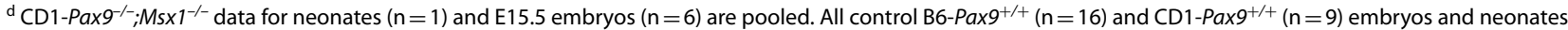

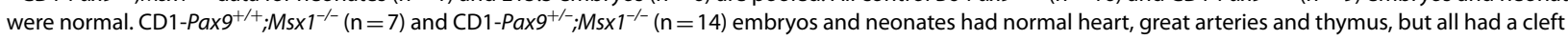
palate

(See figure on next page.)

Fig. 1 Defects in Pax9-/- embryos on a congenic CD1 background. Embryos at E15.5 were imaged by MRI (A-H, I, L, O) and histology $(\mathbf{J}, \mathbf{K}, \mathbf{M}$ $\mathbf{N}, \mathbf{P}, \mathbf{Q})$. A-H Extracardiac defects in CD1-Pax $9^{--}$embryos. A normal palate $(\mathbf{A}, \mathbf{B})$, thymus $(\mathbf{C})$ and hind limb digit (white arrow; $\left.\mathbf{D}\right)$ are seen in

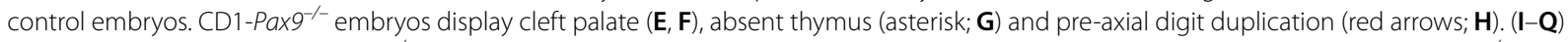

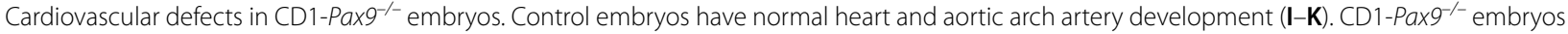
have arch artery defects such as interrupted aortic arch type B (IAA-B), aberrant right subclavian artery (A-RSA), and absent common carotid arteries resulting in the internal and external left carotid arteries (iLC, eLC) arising directly from the aorta and dorsal aorta respectively $(\mathbf{L}, \mathbf{O})$. In the majority of CD1-Pax $9^{-1-}$ embryos the outflow tract was unaffected $(\mathbf{L}-\mathbf{N})$ although double outlet right ventricle (DORV) with interventricular communication (IVC) was infrequently observed (-O-Q). AD, arterial duct; Ao, aorta; BC, brachiocephalic artery; $C$, cleft palate; LCC/RCC, left/right common carotid artery; LSA/RSA, left/right subclavian artery; LV/RV, left/right ventricle; P, palate; PT, pulmonary trunk; Th, thymus. Scale bars: $500 \mu \mathrm{m}$

E10.5, we employed two promoter specific Cre expressing lines, Pax9 $9^{C r e}$ [3] and $M s x 1^{\text {Cre-ERT2 }}$ [31], with the latter injected intraperitoneally with Tamoxifen the day before collection to activate Cre expression. Following $\mathrm{X}$-Gal staining of whole embryos, sections were produced to examine tissue expression in more detail. This demonstrated that $\operatorname{Pax} 9$ is specifically expressed in the pharyngeal endoderm at E10.5 (Fig. 2A-C). Msx1, on the other hand, is expressed within the pharyngeal arches in presumed NCC (Fig. 2D-F). No endoderm staining of Msx 1 was observed. To further assess the non-overlapping expression of $\operatorname{Pax} 9$ and $M s x 1$ in the pharyngeal arches we employed single cell transcriptomics using the Fluidigm C1 System. From dissociated E9.5 caudal pharyngeal arches, the transcriptome of 86 single cells were individually analysed for gene expression (Additional file 5: Table S1). Candidate genes for each pharyngeal tissue were selected as markers for each cell type: $P a x 9$ for endoderm $(\mathrm{n}=13), F g f 8$ and Tfap $2 a$ for ectoderm $(\mathrm{n}=5)$, Hoxa 2 and Pax3 for NCC $(\mathrm{n}=60)$ and Pecam1 and Flt1 for endothelial cells $(\mathrm{n}=3)$ (Fig. 2G). We could not, however, confidently identify any mesoderm cells in this population. We identified 25 cells expressing $M s x 1$ and 13 cells expressing Pax9 (Fig. 2H). Three of these cells expressed Msx1 and Pax9, but almost all Msx1 positive cells $(24 / 25)$ also expressed the NCC markers Hoxa2 and Pax3 (Fig. 2I). A subset of Msx 1 positive cells also expressed the smooth muscle cell markers Pdgfrb and Tagln (2/7). Collectively this data demonstrates that $M s \times 1$ and $\operatorname{Pax} 9$ do not overlap in their expression within the pharyngeal arches at mid-embryogenesis, with $\operatorname{Pax} 9$ specifically expressed in the pharyngeal endoderm and $M s \times 1$ in NCC and their derivatives.

To investigate whether $\operatorname{Pax} 9$ and $M s x 1$ functionally interact in cardiovascular development, $\mathrm{Pax} 9^{+/-}$and $M s x 1^{+/-}$mice, with both lines congenic on a CD1 background, were crossed to produce compound mutant embryos and neonates for analysis. Double heterozygous mice (i.e. $\operatorname{Pax} 9^{+/-} ; M s x 1^{+/-}$) were viable, fertile, and phenotypically normal except for the previously recognised absence of the lower teeth [14]. $\operatorname{Pax}^{+/-}$ $; M s x 1^{+/-}$mice were intercrossed to produce all possible 

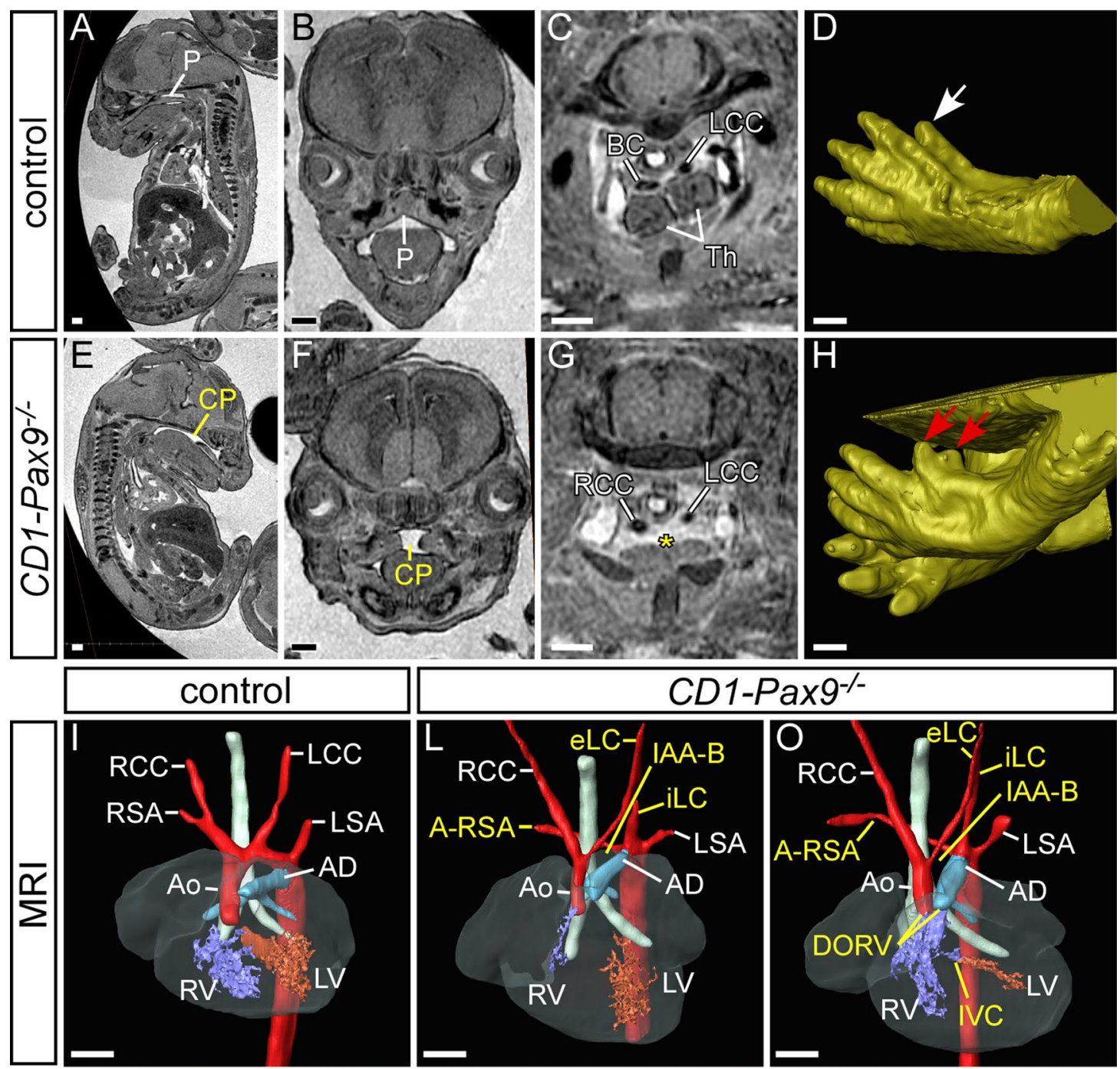

Pax ${ }^{-/}$
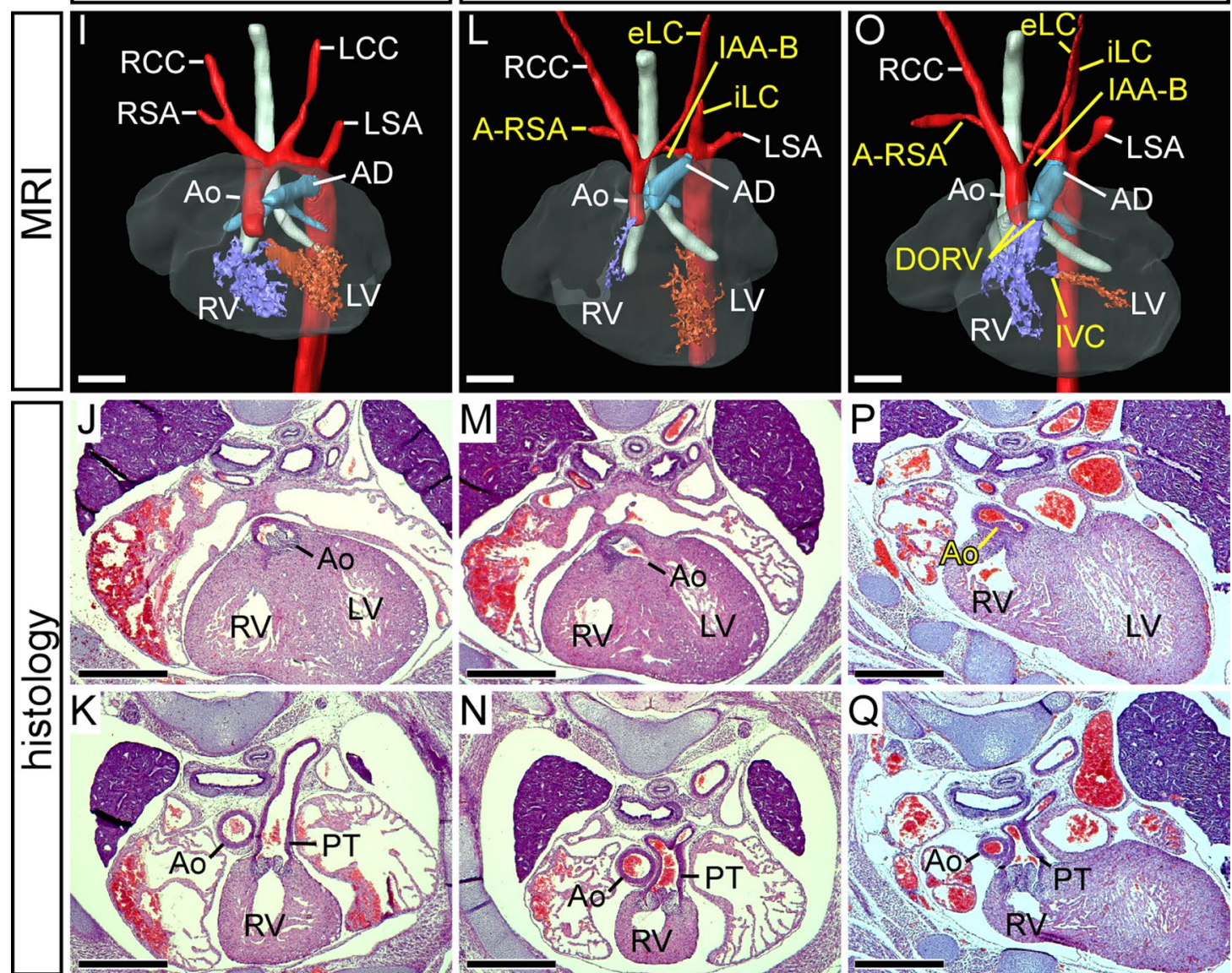

LV

Fig. 1 (See legend on previous page.) 


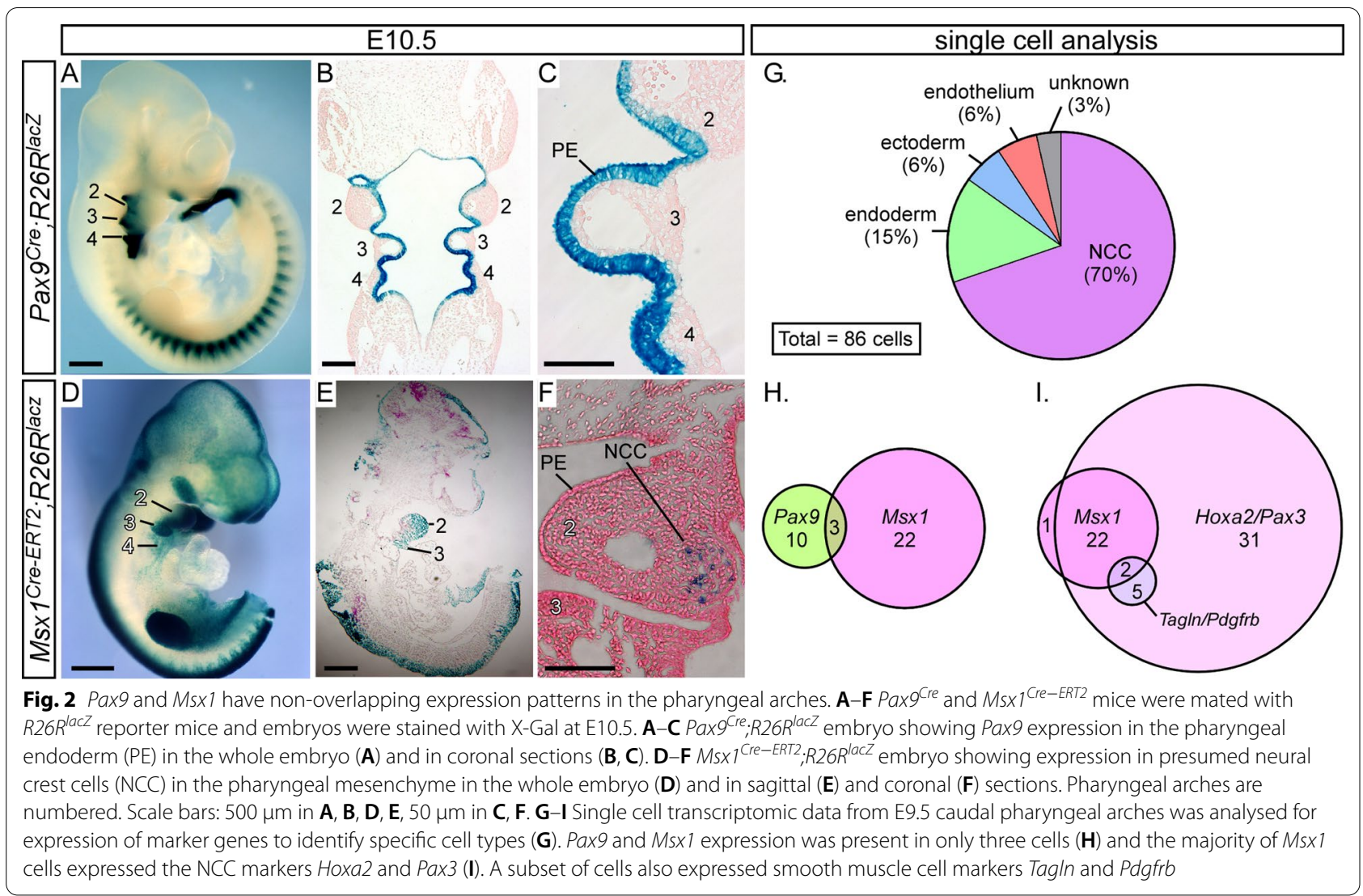

Pax9;Msx 1 genotypes. We confirmed that $M s x 1^{-/-}$mice on a CD1 background have cleft palate but no cardiovascular defects as previously reported [12, 19], and this was also found for the $\mathrm{Pax} \mathrm{9}^{+/-} ; M s \times 1^{-/}$genotype (Additional file 4: Table S2). For the $\mathrm{Pax}^{-/-} ; M s x 1^{+/-}$ genotype, 18 embryos at E15.5 and 20 neonates were collected and examined, revealing a highly significant reduction in IAA-B, with or without A-RSA $(p<0.001)$ when compared with CD1-Pax $9^{-/-}$mice (Fig. 3A-D, F; Table 1). There was also a significant reduction in the incidence of absent common carotid arteries, a hallmark of the B6-Pax $9^{-/-}$cardiovascular phenotype $(p<0.05)$ [3] (Table 1), and a very low incidence of DORV (one case in 29 mutants examined; Fig. 3E). In our initial analysis, A-RSA referred to the right subclavian artery being retro-esophageal, isolated, or of a cervical origin. When this data was further analysed the incidence of retroesophageal right subclavian artery (RE-RSA) was seen to be significantly reduced in $\operatorname{Pax}^{9^{-/-}} ; M s x 1^{+/-}$embryos $(p<0.01)$ (Fig. 3G) and cervical origin of the right subclavian artery (cRSA) was found to be significantly increased $(p<0.05)$ (Fig. 3H). Cervical origin of the aorta (cAo) was also increased significantly $(p<0.05)$ (Fig. 3I). Wild type $(\mathrm{n}=2), \mathrm{Pax}^{9^{-/-}}(\mathrm{n}=4)$ and $\mathrm{Pax}^{-/-} ; \mathrm{Msx}^{+/-}$ $(n=6)$ embryos at E12.5 were analysed by $\mu \mathrm{CT}$ to assess the remodelling of the aortic arch arteries. This revealed that the 3rd and 4th PAAs were absent or aberrant in all $\mathrm{Pax}^{-/-}$embryos as expected [3], whereas in $\operatorname{Pax}^{-}$ ${ }^{1-} ; M s \times 1^{+/-}$embryos the 3rd and 4th PAAs were maintained in $67 \%(8 / 12)$ and $58 \%(7 / 12)$ of cases, respectively $(p<0.05$; Fig. 3J-M; Table 2).

It therefore appears that mice deficient for $\operatorname{Pax} 9$ and heterozygous for $M s x 1$ (i.e. $\operatorname{Pax} 9^{-/-} ; M s x 1^{+/-}$) present with alternative arch artery defects when compared to $\operatorname{Pax}^{-/-}$mice. These compound mutant mice, however, did show the other $\mathrm{Pax}^{-/-}$associated developmental defects affecting the palate, thymus and digits (as shown in Fig. 1) [4]. Overall, lack of one Msx1 allele in the context of $\operatorname{Pax} 9$ deficiency appeared to rescue the cardiovascular phenotype to a degree, with the incidence of fatal lesions, such as IAA-B, reduced and replaced with the potentially non-lethal defect of cervical origin of the aortic arch.

To further examine the effect of genetic background on the $\mathrm{Pax}^{-/-}$cardiovascular phenotype, and to also analyse the effect of $M s x 1$ heterozygosity, intra-cardiac ink injections were performed on CD1-Pax $9^{-/-}$and CD1-Pax $9^{-}$ ${ }^{/-} ; M s \times 1^{+/-}$embryos at E10.5 to visualise the patency of the developing PAAs (Fig. 3N). Data for CD1-Pax $9^{-/-}$ embryos $(n=9)$ was first compared to our published ink 

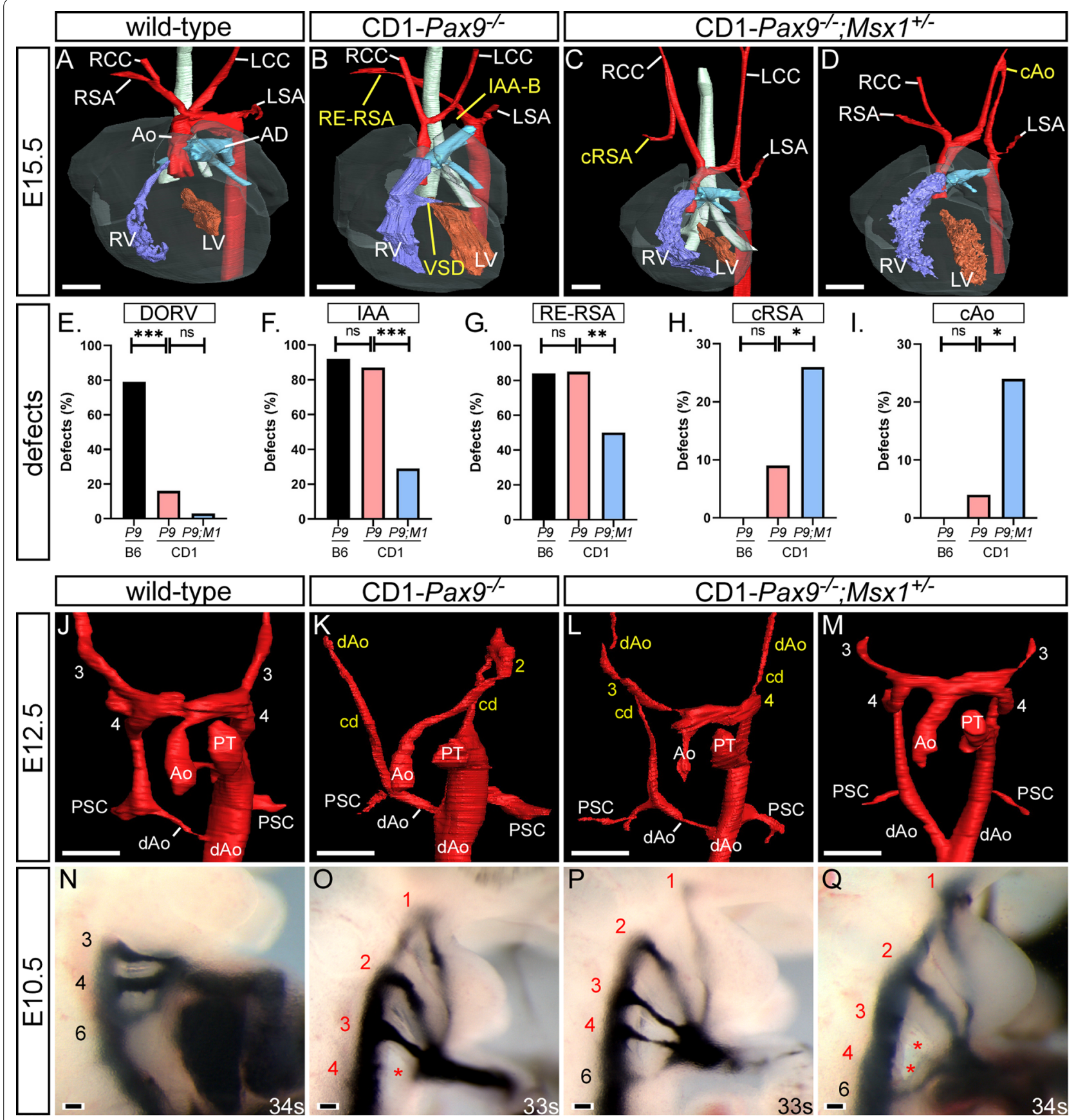

Fig. $3 \mathrm{Ms} \times 1$ haploinsufficiency modifies the $\mathrm{Pax}^{-/-}$cardiovascular phenotype. Embryos were imaged by $\mu \mathrm{CT}$ at E15.5 (A-D) and E12.5 (J-M), and following intracardiac ink injection at E10.5 (N-Q). A Control embryo with normal heart and aortic arch artery development. B CD1-Pax $9^{-/-}$embryos have defects such as interrupted aortic arch type B (IAA-B), retro-esophageal right subclavian artery (RE-RSA) and ventricular septal defect (VSD). A proportion of $\mathrm{CD} 1-\mathrm{Pax}^{-/-} ; \mathrm{Ms} \times 1^{+/-}$embryos had cervical right subclavian artery (CRSA; C) or cervical aortic arch (CAo; D). E-I Defect frequencies

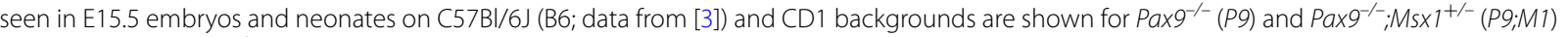
genotypes. CD1-Pax $9^{-1-}$ mice have a significantly reduced penetrance of outflow tract defects such as DORV (E) although 4th PAA-derived defects

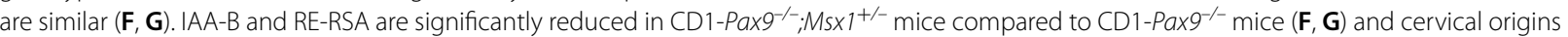
of the RSA (cRSA; H) and aorta (cAo; I) are increased. Fisher's exact test for associations. ns, not significant; ${ }^{*} p<0.05,{ }^{* *} p<0.01,{ }^{* * *} p<0.001$. J At E12.5 the aorta ( $\mathrm{Ao}$ ) and pulmonary trunk (PT) are septated and the right dorsal aorta (dAo) is regressing. $\mathbf{K}$ In $\mathrm{CD} 1-\mathrm{Pax} 9^{-/-}$embryos the PAA are abnormal with the 3rd and 4th PAA bilaterally absent, and the carotid duct (cd) persisting bilaterally. L, $\mathbf{M} \ln$ CD 1-Pax $9^{-1-} ; M s \times 1^{+/-}$embryos the 3rd and 4th

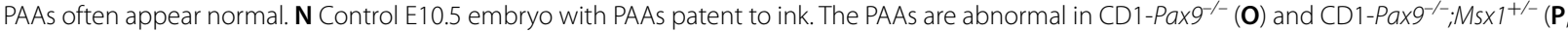
Q) embryos. Somite counts (s) are indicated. AD, arterial duct; LCC/RCC, left/right common carotid artery; LSA/RSA, left/right subclavian artery; LV/ RV, left/right ventricle; PSC, primitive subclavian complex. Scale bars: $500 \mu \mathrm{m}$ in A-D, $250 \mu \mathrm{m}$ in J-M, $100 \mu \mathrm{m}$ in N-Q 
Table 2 Cardiovascular defects in Pax9:Msx1 mutant embryos at E12.5

\begin{tabular}{|c|c|c|c|}
\hline Genotype & $\mathrm{n}$ & Absent 3rd PAA & Absent 4th PAA \\
\hline Control & 2 & $0 / 4$ & $0 / 4$ \\
\hline CD1-Pax $9^{-/-}$ & 4 & $7 / 8$ & $8 / 8$ \\
\hline $\mathrm{CD} 1-\mathrm{Pa} \times 9^{-/-} ; \mathrm{Ms} \times 1^{+/-}$ & $6 a$ & $4 / 12^{*}$ & $5 / 12^{*}$ \\
\hline
\end{tabular}

Embryos were assessed by $\mu C T$ and the 3rd and 4th PAAs (i.e. two of each per embryo) scored for being absent in each genotype. PAA defects in CD1-Pax9 ${ }^{-}$ ${ }_{--}^{-} M M_{x} 1^{+/-}$embryos were significantly reduced when compared to CD1-Pax $9^{-/-}$ embryos

PAA pharyngeal arch artery

${ }^{*} p<0.05$ (Fisher's exact test for associations)

${ }^{a}$ Two embryos were normal with no PAA defects

injected B6- $\operatorname{Pax} 9^{-/-}$embryos $(\mathrm{n}=20)$ [3]. This analysis revealed that, like B6-Pax $9^{-/-}$embryos, the 4th PAAs in CD1-Pax $9^{-/-}$embryos were bilaterally non-patent to ink and therefore considered to be absent at this stage. The 3rd PAAs in CD1-Pax $9^{-/-}$embryos were also similarly affected as B6-Pax $9^{-/-}$embryos in the majority of cases (Fig. 3O; Table 3). Approximately half of B6-Pax $9^{-/-}$ embryos also had aberrantly persisting 1st and/or 2nd PAAs patent to ink, and this increased to $78 \%(p=0.41)$ and $89 \%(p<0.05)$ respectively in CD1-Pax $9^{-/}$embryos. CD1-Pax $9^{-/-} ; M s \times 1^{+/-}$embryos $(\mathrm{n}=16)$ also displayed bilateral defects of the 4th PAAs although 37.5\% (6/16) embryos had at least one vessel that was hypoplastic rather than absent, which is significantly different to CD1-Pax $9^{-/-}$embryos $(p<0.05$; Fig. 3P, Q; Table 3; Additional file 1). There was a significant reduction in the incidence of 3rd PAA defects seen in CD1-Pax $9^{-/-}$ ;Ms $x 1^{+/-}$embryos compared with CD1-Pax $9^{-/-}$embryos ( $25 \%$ vs. $89 \% ; p<0.005)$. The reduction in persistent 1 st and 2nd PAAs observed, however, was not significant.

Breeding double heterozygous mice also produced double null (i.e. $\operatorname{Pax} 9^{-/-} ; M s x 1^{-/-}$) embryos $(\mathrm{n}=6$ at E15.5, $\mathrm{n}=1$ at E12.5, $\mathrm{n}=2$ at E10.5), and one neonate, for analysis (Additional file 2; Table 1). From the mutant neonates and embryos at E15.5, two presented with IAA-B and A-RSA (Additional file 2H), and one of these also had DORV. Interestingly, $\operatorname{Pax} 9^{-/-} ; M s x 1^{-/-}$mice did not have the pre-axial digit duplication seen in $\operatorname{Pax}^{-/-}$ mice (Additional file 2G). Analysis of the three $\mathrm{Pax} 9^{-/-}$ ;Ms $x 1^{-/-}$embryos at E12.5 and E10.5 by HREM and ink injection showed that the PAA defects were similar to $\mathrm{Pax}^{-/-}$embryos at these stages (Additional file $2 \mathrm{~L}-\mathrm{N}$ ). The incidence of IAA-B in $\operatorname{Pax} 9^{-/-} ; M s x 1^{-/-}$neonates and E15.5 embryos was the same as seen in $\operatorname{Pax}^{-/-} ; M s x 1^{+/-}$ neonates and E15.5 embryos (Table 1) but the majority of double nulls $(\mathrm{n}=5 / 7 ; 71 \%)$ had a normal cardiovascular system at these stages.

To investigate if cell fate within the pharyngeal arches was affected in CD1-Pax9;Msx 1 mutant embryos, cell death and proliferation were assessed. There was no significant difference in the levels of apoptosis and proliferation between the cells of the different pharyngeal tissue layers in control, CD1-Pax $9^{-/-}$and

Table 3 Pharyngeal arch artery defects in mutant E10.5 embryos

\begin{tabular}{|c|c|c|c|c|c|c|c|c|}
\hline \multirow[t]{2}{*}{ Genetic background } & \multirow[t]{2}{*}{$\mathbf{n}$} & \multirow[t]{2}{*}{ PAA } & \multirow[t]{2}{*}{ Abnormal } & \multirow[t]{2}{*}{ Unilateral } & \multirow[t]{2}{*}{ Bilateral } & \multicolumn{3}{|c|}{ Bilateral defects } \\
\hline & & & & & & Present & Hypo/Int/Abs & Absent \\
\hline \multirow[t]{4}{*}{ B6-Pax9 $9^{-1-a}$} & 20 & 1 & $11(55 \%)$ & 1 & 10 & 9 & 1 & 0 \\
\hline & & 2 & $8(40 \%)$ & 3 & 5 & 4 & 1 & 0 \\
\hline & & 3 & $15(75 \%)$ & 3 & 12 & - & 8 & 4 \\
\hline & & 4 & $20(100 \%)$ & 1 & 19 & - & 3 & 16 \\
\hline \multirow[t]{4}{*}{ CD1-Pax9 ${ }^{-/-}$} & 9 & 1 & 7 (78\%) & 1 & 6 & 6 & 0 & 0 \\
\hline & & 2 & $8(89 \%) *$ & 1 & 7 & 7 & 0 & 0 \\
\hline & & 3 & $8(89 \%)$ & 0 & 8 & - & 3 & 5 \\
\hline & & 4 & $9(100 \%)$ & 0 & 9 & - & 0 & 9 \\
\hline \multirow[t]{4}{*}{$\mathrm{CD} 1-\mathrm{Pax}^{-/-} ; \mathrm{Ms} \mathrm{1}^{+/-}$} & 16 & 1 & $8(50 \%)$ & 0 & 8 & 8 & 0 & 0 \\
\hline & & 2 & $8(50 \%)$ & 0 & 8 & 8 & 0 & 0 \\
\hline & & 3 & $4(25 \%)^{* *}$ & 0 & 4 & - & 3 & 1 \\
\hline & & 4 & $16(100 \%)$ & 0 & 16 & - & $6^{*}$ & 10 \\
\hline
\end{tabular}

Embryos were collected at E10.5 and assessed for pharyngeal arch artery (PAA) defects by intracardiac ink injection

${ }^{* *} p<0.005,{ }^{*} p<0.05$ (Fisher's exact test for associations)

${ }^{\text {a }}$ Data for Pax $9^{-/-}$embryos on a C57BI/6J (B6) genetic background have been published [3]. For Pax9 ${ }^{-/-}$embryos, each left and right PAA 1-4 was scored as having a unilateral or bilateral defect, and the bilateral defects categorised as either present, a combination of hypoplastic, interrupted and/or absent (Hypo/Int/Abs)

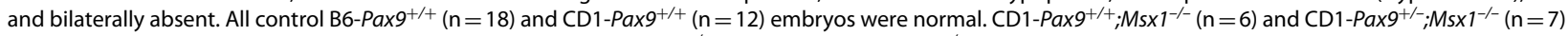
embryos were normal. The increase in abnormal 2nd PAAs in CD1-Pax $9^{-/-}$compared with B6-Pax $9^{-/-}$embryos is significant. The decrease in 3 rd PAA defects, and the increase in hypoplastic 4th PAA defects, in $\mathrm{CD} 1-\mathrm{Pax}^{-/-} ; \mathrm{Ms} \times 1^{+/-}$compared with $\mathrm{CD} 1-\mathrm{Pax}^{-/-}$embryos is significant 


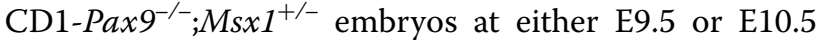
( $n \geq 3$ per genotype and stage) (Additional file 3 ). In B6- $\mathrm{Pax} 9^{-/-}$embryos a significantly reduced number of NCC observed in the 3rd and 4th pharyngeal arches at E10.5 has been described [3]. We firstly counted the number of cells in the pharyngeal arch mesenchyme of CD1 congenic mutant mice as this is predominantly comprised of NCC $(n \geq 3$ per genotype and stage;
Fig. 4A). This revealed that at E9.5 there was a significant reduction in cell number in the 3rd pharyngeal arch

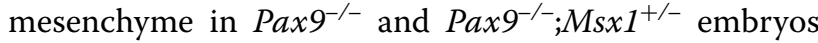
compared to controls $(p<0.05)$. At E10.5 there was also a significant reduction in the number of mesenchymal cells in the 3rd pharyngeal arch of $\operatorname{Pax}^{-/-}$embryos $(p<0.001)$, but the reduction in cell number in $\operatorname{Pax}^{-/-} ; M s \times 1^{+/-}$ embryos was not significantly different to controls in this

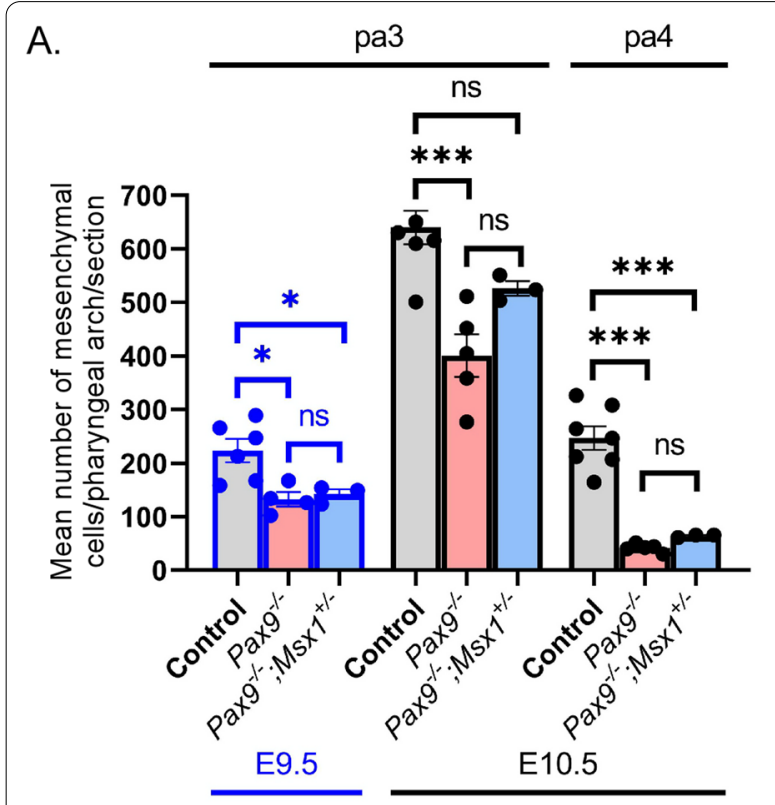

B.

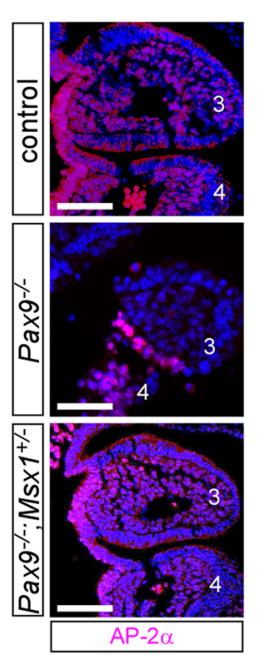

C.

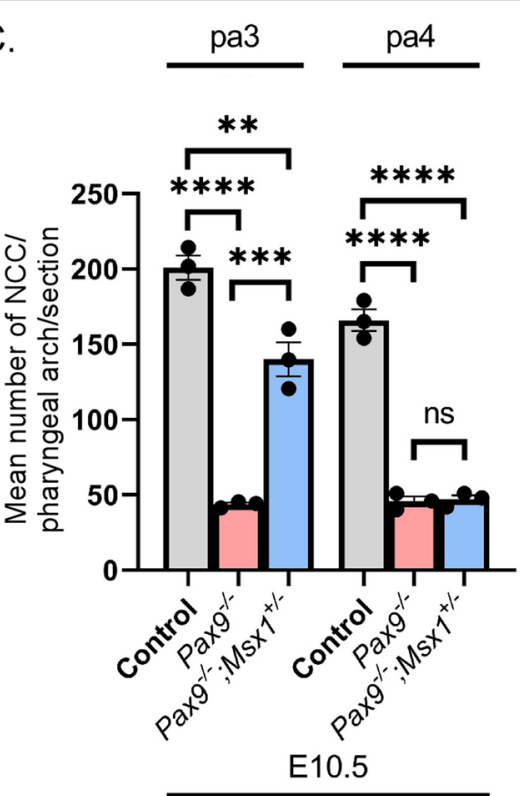

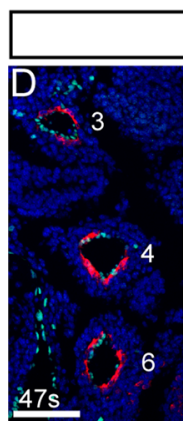

\section{control}
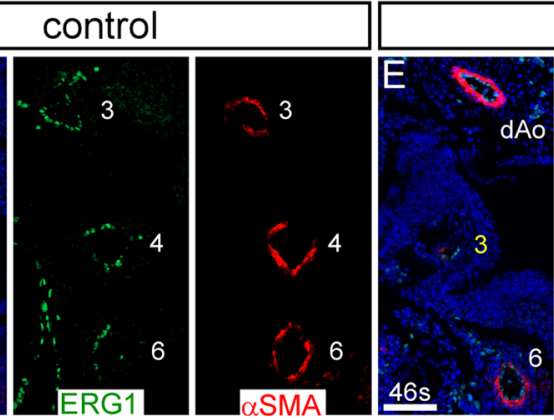

\section{$\operatorname{Pax} 9^{-1-10}$}

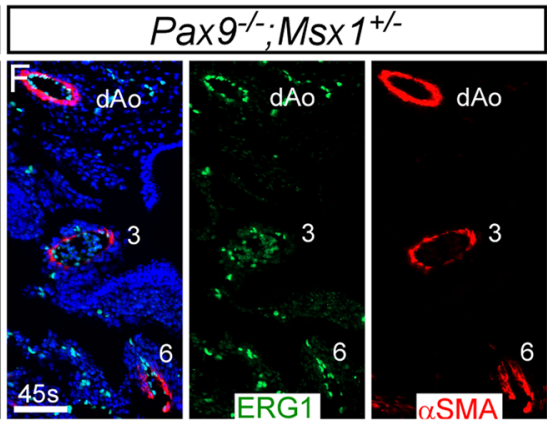

Fig. 4 Msx1 haploinsufficiency rescues the 3rd pharyngeal arch artery defect in $\mathrm{Pax}^{-1-}$ embryos. A The total number of cells within the

mesenchyme of the 3rd and 4th pharyngeal arches (pa) per section were counted at E9.5 and E10.5 in control $(n \geq 5), C D 1-P a \times 9^{-/-}(n \geq 4)$ and

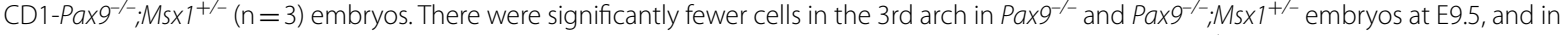
the 4th arch at E10.5, compared to control. In the 3rd arch at E10.5 there were significantly fewer cells in Pax $9^{-/-}$embryos but the reduction in cell number was not significant in Pax9 $9^{-/-} ; M_{S x} 1^{+/-}$embryos. B Immunostaining for neural crest cells (NCC) using an anti-AP-2a antibody was performed

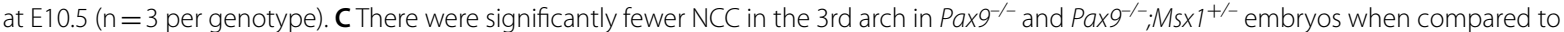

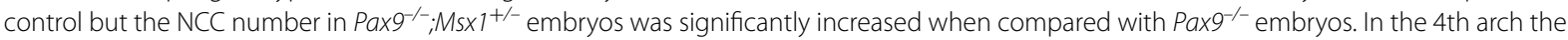
reduction in NCC was significant in both mutant genotypes when compared to control. One-way ANOVA with Tukey's multiple comparisons test. ns, not significant; ${ }^{*} p<0.05,{ }^{* *} p<0.01,{ }^{* * *} p<0.001,{ }^{* * * *} p<0.0001$. D-F E11.5 embryo sections ( $\mathrm{n}=6$ per genotype) were immunostained using an anti-aSMA antibody for smooth muscle cells (SMC) and an anti-ERG antibody for endothelium. In all control embryos, SMC surrounded the 3rd,

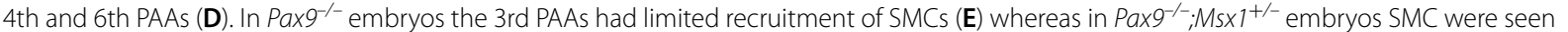
surrounding the 3rd PAAs (F). There are no 4th PAAs in $\mathrm{Pax}^{-/-}$and $\mathrm{Pax}^{-/-} ; \mathrm{Ms} \mathrm{1}^{+/-}$embryos. Somite counts (s) are indicated. Scale bars: $50 \mu \mathrm{m}$ in B, $100 \mu \mathrm{m}$ in D-F 
tissue. In the 4th pharyngeal arch, however, there was a significant reduction in cell number in both $\mathrm{Pax}^{-/-}$and $\operatorname{Pax}^{-/-} ; M s \times 1^{+/-}$embryos $(p<0.001$; Fig. 4A). This data, therefore, suggests that there is a reduction in NCC number in the 4th pharyngeal arch of $\mathrm{Pax}^{-/-}$and $\mathrm{Pax}^{-/-}$ $; M s x 1^{+/-}$embryos, but the reduction in cell number in the 3rd pharyngeal arch of $\operatorname{Pax}^{-/-} ; M s x 1^{+/-}$embryos at E10.5 is not significantly reduced when compared to controls. To validate this observation specifically for NCC, we immunostained coronal sections of E10.5 embryos $(\mathrm{n}=3$ per genotype) with an anti-AP- $2 \alpha$ antibody which labels NCC (Fig. 4B). This confirmed our mesenchymal cell counting data and demonstrated that the number of NCC in the 3rd pharyngeal arch of $\mathrm{Pax}^{-/-} ; \mathrm{Ms} x 1^{+/-}$ embryos at E10.5 was significantly increased when compared with $\mathrm{Pax}^{-/-}$embryos $(\mathrm{p}<0.001)$. The number of NCC in the 4th pharyngeal arch was significantly reduced in both $\operatorname{Pax}^{-/-}$and $\operatorname{Pax}^{-/-} ; \mathrm{Msx}^{+/-}$embryos when compared to controls $(p<0.0001$; Fig. $4 \mathrm{C})$.

In B6-Pax9 $9^{-/}$embryos the reduction in SMC surrounding the 3rd PAAs was linked to the failure of this vessel to be maintained resulting in an absent common carotid artery at the foetal stage [3]. To investigate this

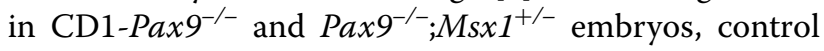
and mutants at E11.5 were immunostained using antibodies raised against ERG1 and smooth muscle actin for endothelium and SMC respectively $(n=6$ of each genotype examined; Fig. 4D-F). This staining revealed that, like B6-Pax $9^{-/-}$embryos, SMC recruitment to the 3rd PAA was greatly reduced or absent in CD1-Pax $9^{-/-}$ embryos (Fig. 4E). In $\operatorname{Pax} 9^{-/-} ; M s x 1^{+/-}$embryos, however, SMC were observed surrounding the 3rd PAAs (Fig. 4F).

Collectively, these data show that the reduced number of NCC in the 3rd pharyngeal arch in $\operatorname{Pax}^{-/-}$embryos is rescued to some extent in $\operatorname{Pax}^{-/-} ; M s x 1^{+/-}$embryos. Along with the concomitant recruitment of SMC to the 3rd PAA, this suggests a developmental mechanism to explain the reduced aortic arch artery severity in mice with $\operatorname{Pax} 9$ deficiency coupled with $M s x 1$ heterozygosity. $\mathrm{Pax}^{-/-}$mice die in the neonatal period, presumably from arterial duct-dependent defects such as IAA-B caused by failure of the left 4th PAA to form, as well as absent common carotid arteries caused by the collapse of the 3rd PAAs [3]. $\operatorname{Pax}^{-/-} ; M s x 1^{+/-}$mice also died after birth but with a much lower incidence of IAA-B and absent common carotid arteries, and a higher occurrence of other arch artery defects such as cervical origins of the aortic arch and right subclavian artery were observed. Analysis at mid-embryogenesis showed that, although morphogenesis of the 4th PAAs was affected in all $\operatorname{Pax} 9^{-}$ ${ }^{-} ; M s \times 1^{+/-}$embryos, a proportion of embryos had a mildly affected 4th PAA. Moreover, there were fewer embryos with 3rd PAA defects and this was linked to the maintenance of the 3rd PAAs which were invested with SMC. We therefore hypothesised that Msx 1 heterozygosity, rather than rescuing arch artery defects, altered the type of defect to one that is apparently compatible with a functioning systemic circulation. For example, a 3rd PAA in combination with an absent left 4th PAA and a persistent carotid duct may remodel to a cervical aortic arch.

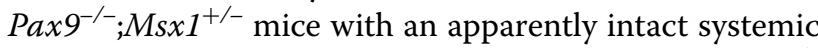
circulation, however, still died soon after birth. $\operatorname{Pax} 9^{-/-}$ and $\mathrm{Pax}^{-/-} ; \mathrm{Msx}^{+/-}$mice also have a cleft secondary palate, and we speculated that this could theoretically compromise postnatal survival independent of the cardiovascular defects $[4,7]$. We therefore further hypothesised that mutant mice with a normal palate and an intact systemic cardiovascular system could survive the neonatal period following closure of the arterial duct. To engineer this configuration we used Isl1Cre mice [32] in conjunction with a Pax9-floxed allele [33]. Isl1Cre causes recombination in the second heart field (SHF), encompassing the pharyngeal endoderm, and the developing limb, two domains where $\operatorname{Pax} 9$ is also expressed [32, 34]. We expected that the palate would not be affected in these mice as the cleft palate observed with $\operatorname{Pax} 9$ deficiency is caused by a lack of expression in NCC $[3,33]$, a cell type with only minimal activity of Isl1Cre [35]. The

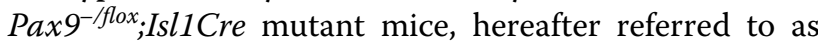
$\operatorname{Pax} 9^{\triangle S H F}$, should therefore develop the typical $\operatorname{Pax}^{-/-}$ cardiovascular defects but without a cleft palate. Firstly, to demonstrate the efficacy of deleting $\operatorname{Pax} 9$ from the Is 1 Cre domain, we generated $\operatorname{Pax} 9^{\triangle S H F}$ mutant mice on a $\mathrm{C} 57 \mathrm{Bl} / 6 \mathrm{~J}$ genetic background. From nine Pax $9^{\triangle S H F}$ embryos at E15.5 examined by MRI, all presented with the typical $\mathrm{Pax}^{-/-}$phenotype, affecting the cardiovascular system, thymus and digit formation, although the palate was normal as predicted (Fig. 5; Table 4). There was no significant difference from the cardiovascular defects observed in B6-Pax9 ${ }^{-/-}$mice.

We next generated $\operatorname{Pax} 9^{\Delta S H F}$ and $\operatorname{Pax} 9^{\Delta S H F} ; M s x 1^{+/-}$ neonates for analysis on a CD1 genetic background. Due to the complex mating scheme required to generate mutant mice we only collected neonates so as to conserve the dams for subsequent breeding. All neonates that were found dead soon after birth were collected and analysed for arch artery defects, cleft palate and pre-axial digit duplication. All surviving neonates were culled five days after birth and examined the same way. Genotyping revealed that all neonates found dead on the day of birth had a $\mathrm{Pax}^{-/-}$genotype. All control genotypes analysed $(\mathrm{n}=5)$ had a normal palate and arch arteries (Fig. 6A-C). All $\mathrm{Pax}^{-/-}$neonates $(\mathrm{n}=5)$ presented with IAA-B and A-RSA as well as a cleft palate and pre-axial digit duplication (Fig. 6D-F). From two $\mathrm{Pax} 9^{-/-} ; \mathrm{Ms}_{x} \mathrm{1}^{+/-}$neonates recovered from this cross, both had a cleft palate and 

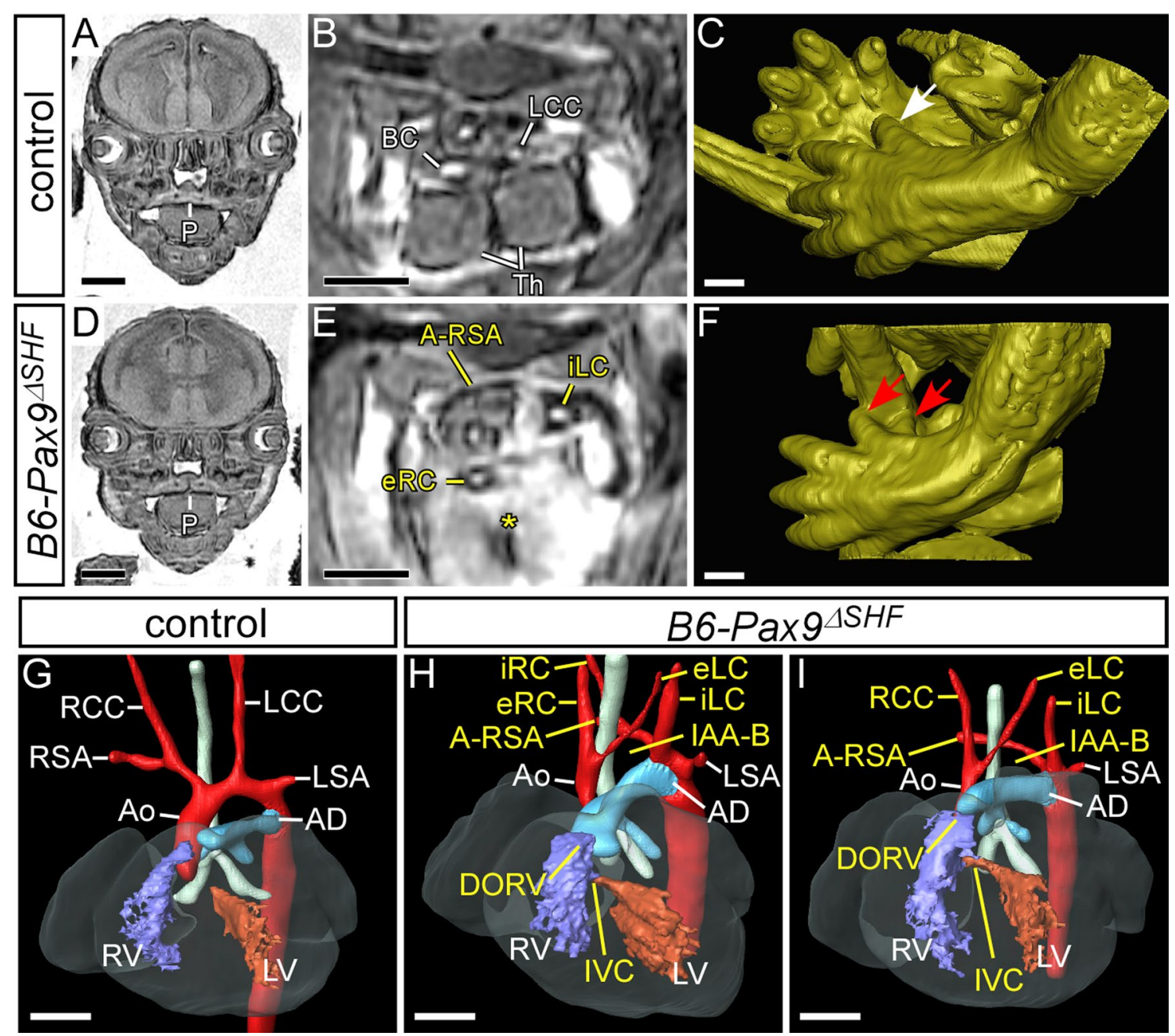

Fig. 5 Deletion of Pax9 from the second heart field in C57BI/6 congenic mice recapitulates the Pax $9^{-/-}$cardiovascular phenotype. Embryos at E15.5 were imaged by MRI. A-C Pax9+/flox; Is/1 Cre control embryos had normal development of the palate (A), thymus (B) and hind limb digit (white arrow;

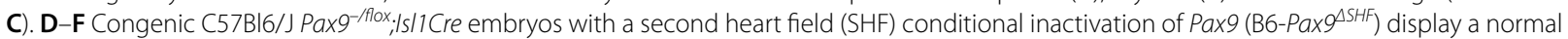
palate (D), absent thymus (asterisk; E) and pre-axial digit duplication (red arrows; F). G-I Cardiovascular defects in B6-Pax9 ${ }^{\Delta S H F}$ embryos. G Control

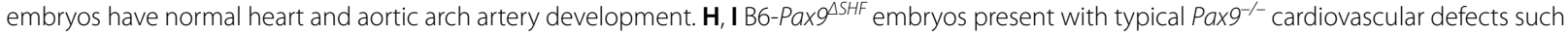
as double-outlet right ventricle (DORV) with interventricular communication (IVC), interrupted aortic arch type B (IAA-B), aberrant right subclavian artery (A-RSA), and absent common carotid arteries resulting in the internal and external carotid arteries (iLC, eLC, iRC, eRC) arising directly from the aorta and dorsal aorta respectively. $\mathrm{AD}$, arterial duct; Ao, aorta; $\mathrm{BC}$, brachiocephalic artery; LCC/RCC, left/right common carotid artery; LSA/RSA, left/ right subclavian artery; LV/RV, left/right ventricle; P, palate; Th, thymus. Scale bars: $500 \mu \mathrm{m}$

pre-axial digit duplication, one had a cervical right subclavian artery, and the other a cervical aortic arch. Only one $\operatorname{Pax} 9^{\triangle S H F}$ neonate was recovered, but showed the expected arch artery defects (IAA-B and A-RSA) and pre-axial digit duplication seen in $\operatorname{Pax}^{-/-}$mice, although the palate was normal (Fig. 6G-I; Table 4). Eight neonates with the $\operatorname{Pax} 9^{\Delta S H F} ; M s x 1^{+/-}$genotype (i.e. Pax9 deleted from the SHF in conjunction with Msxi heterozygosity) were recovered, all found dead on the day of birth. The pre-axial digit duplication was seen, but the palate was unaffected, and the aorta and right subclavian artery were either normal $(n=6)$ or of cervical origin $(n=2$; Fig. 6J-L; Table 4). Histology confirmed that the outflow tract, arterial valves and ventricular septum were normal. The cardiovascular system of $\operatorname{Pax} 9^{\Delta S H F} ; M s x 1^{+/-}$neonates was therefore normal or had a phenotype theoretically compatible with a functioning systemic circulation, and an unaffected palate, yet these mice died on the day of birth.

As $\operatorname{Pax} 9$ deficiency has been shown to cause bone malformations such as pre-axial digit duplication and cleft palate [4] we investigated the skeletons of control, 
Table 4 Cardiovascular defects in second heart field mutant embryos and neonates

\begin{tabular}{|c|c|c|c|c|c|c|c|}
\hline $\begin{array}{l}\text { Genetic background- } \\
\text { genotype and stage }\end{array}$ & $\mathbf{n}$ & VSD & DORV + IVC & cAo & $\mathrm{IAA}-\mathrm{B} \pm \mathrm{A}-\mathrm{RSA}$ & A-RSA & Absent CC \\
\hline $\begin{array}{l}\text { B6-Pax9 } \triangle \text { SHF } \\
\text { E15.5 }\end{array}$ & 9 & $1 / 9(11 \%)$ & $5 / 9(56 \%)$ & 1/9 (11\%) & 8/9 (89\%) & 1/9 (11\%) & $9 / 9(100 \%)$ \\
\hline $\begin{array}{l}\text { CD1-Paxפ } 9^{\triangle S H F} \\
\text { Neonate }\end{array}$ & 1 & N/A & N/A & 0 & 1 & 0 & 1 \\
\hline $\begin{array}{l}\text { CD1-Pax9 }{ }^{\triangle S H F} ; M_{S x} 1^{+/-} \\
\text {Neonate }\end{array}$ & 8 & 0 & 0 & $2 / 8(25 \%)$ & 0 & $2 / 8(25 \%)$ & 0 \\
\hline
\end{tabular}

All mice with $\operatorname{Pax} 9$ conditionally inactivated from the second heart field with $/ \mathrm{s} / 1 \mathrm{Cre}\left(\operatorname{Pax} 9^{\Delta S H F}\right)$ had pre-axial digit duplication, absent thymus and normal palate. N/A, not assessed

A-RSA, aberrant right subclavian artery; cAo, cervical aorta; CC, common carotid artery; DORV + IVC, double outlet right ventricle with interventricular communication; IAA,-B interrupted aortic arch type B; SHF, second heart field; VSD, perimembranous ventricular septal defect

$\operatorname{Pax} 9^{-/-}$and $\operatorname{Pax} 9^{\triangle S H F} ; M s x 1^{+/-}$neonates to see if any phenotype here could explain the neonatal death. Neonatal skeletons were stained for cartilage and bone using alcian blue and alizarin red. All control neonates $(n=5)$ had a normal skeleton (Fig. 7A). The $\operatorname{Pax}^{-/-}(\mathrm{n}=4)$ and $\operatorname{Pax} 9^{\triangle S H F} ; M_{s} \times 1^{+-}(\mathrm{n}=6)$ skeletons all presented with a pre-axial digit duplication on the hind and forelimbs (Fig. 7B, C) as expected. The ulna length for each line was measured and showed there was little difference in neonate size between the genotypes (Fig. 7G). In control neonates the normal hyoid bone, which connects to various ligaments and muscles such as the thyrohyoid and stylohyoid ligaments [36], had a horseshoe-shape, with an elongated and flat body, and two pairs of greater and lesser horns which projected posteriorly and anteriorly, respectively, from the outer borders of the body (Fig. 7D). In the $\mathrm{Pax}^{-/-}$and $\mathrm{Pax}^{\triangle S H F}$;Ms $x 1^{+/-}$mutants, the ossification centre of the body of the hyoid bone was significantly shorter compared to controls $(p<0.0001$; Fig. 7E, $\mathrm{F}, \mathrm{H})$, the lesser horn extended laterally and the greater horn was significantly reduced in length (Fig. 7E, F, I). The angle between the greater and lesser horns was significantly reduced in $\operatorname{Pax}^{-/-}$and $\operatorname{Pax} 9^{\triangle S H F} ; M s x 1^{+/-}$neonates $(p<0.0001)$ when compared to controls (Fig. 7E, F, J). Pax 9 deficiency also causes thyroid cartilage deformities, where the thyroid cartilage is broader and lacks the lateral processes normally connecting the thyroid and cricoid cartilages [4]. Control neonates showed a normal thyroid cartilage with two laminae that fused together anteriorly (Fig. 7K, L). The posterior border of each lamina was free and created the superior and inferior horn projections. In $\mathrm{Pax}^{-/-}$and $\mathrm{Pax} 9^{\Delta S H F} ; M s x 1^{+/-}$neonates the inferior horn of the thyroid cartilage was significantly shorter compared to controls, and the superior horn was reduced to a stump (Fig. $7 \mathrm{M}-\mathrm{Q}$ ). Fused tracheal rings were also observed in $\operatorname{Pax}^{-/-}$neonates (Fig. $7 \mathrm{M}, \mathrm{N}$ ). The hyoid bone and thyroid cartilage are both derived from NCC $[37,38]$ but neonates with a conditional inactivation of $\operatorname{Pax} 9$ from NCC, however, did not have any hyoid bone or thyroid cartilage defects $(n=11$; Fig. $7 R, S)$.

\section{Discussion}

In this study we have shown that mice deficient for $\operatorname{Pax} 9$ on a congenic CD1 background, compared to those congenic for $\mathrm{C} 57 \mathrm{Bl6} / \mathrm{J}$ [3], have a significantly reduced incidence of DORV and do not show bicuspid aortic valve or hypoplastic aorta. The incidence of aortic arch defects, however, are very similar. We have also shown that Pax $9^{-/-}$mice heterozygous for $M s \times 1$ have a significantly reduced incidence of arterial duct-dependent defects but an increase in alternative arch artery defects that could have been compatible with post-natal life in the absence of a cleft palate. Mice with this phenotype, however, did not survive after birth and most likely died from Pax9deficiency causing non-cell autonomous defects to the hyoid bone and thyroid cartilage.

It is well known that changing the genetic background in mouse models of disease may influence the presentation of specific phenotypes due to strain-specific modifiers [27]. For example, Cited2-deficient mice congenic for C57Bl6/J had left-right patterning defects [29] that were not apparent on a mixed genetic background [39]. On a Swiss Webster background mice heterozygous for $T b x 1$ do not show the typical 4th PAA derived arch artery defects [40], and arch artery defects change according to genetic background in $A p 2 a$-null embryos [28]. It is difficult to speculate on a mechanism to explain how the change in the outflow tract phenotype in $\mathrm{Pax}^{-/-}$mice on a different genetic background is controlled. Given that outflow tract defects are typically caused by issues with the SHF [41] it is possible that genetic modifiers on the CD1 background are protective of the SHF, allowing it to proceed with development almost normally. Deletion of $T b x 1$ results in severe cardiovascular defects affecting the outflow tract and arch arteries [42] but the conditional reactivation of $T b x 1$ expression in the SHF mesoderm 

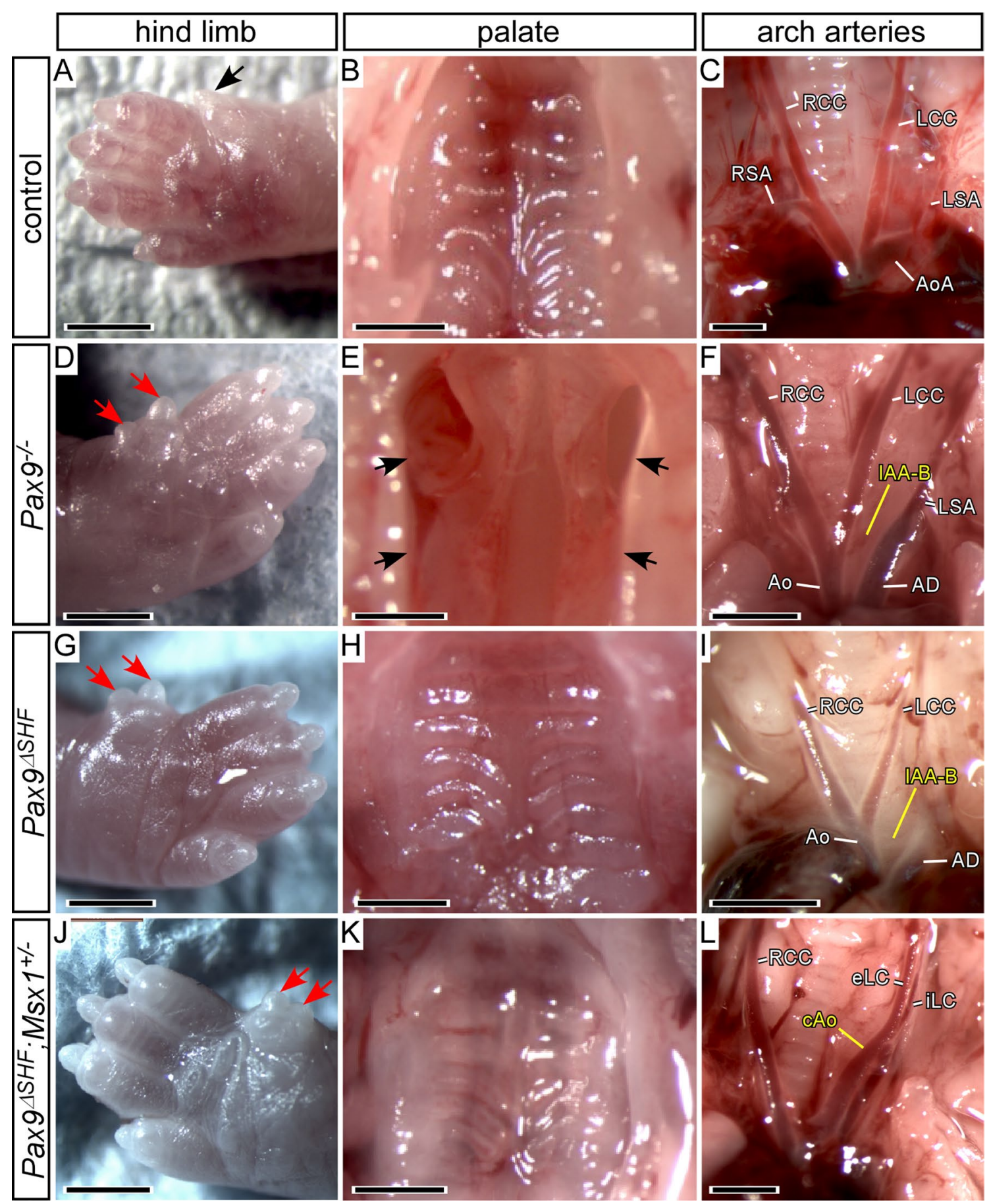

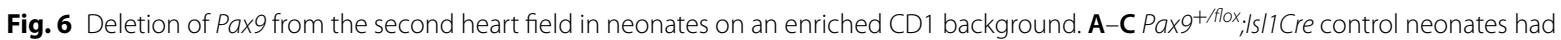
normal hind limb digit (black arrow; A), palate (B) and arch artery (C) development. D-F Pax $9^{-/}$neonates from this cross displayed the typical $\mathrm{Pax9}^{-/-}$phenotype of pre-axial digit duplication (red arrows; $\mathbf{D}$ ), cleft palate (black arrows; $\mathbf{E}$ ) and cardiovascular defects such as interrupted aortic arch type B (IAA-B; F). G-I Only one neonate with Pax9 conditionally inactivated from the second heart field (Pax9 ${ }^{\Delta S H F}$ ) was recovered but showed a pre-axial digit duplication (red arrows; G), a normal palate $(\mathbf{H})$ and IAA-B (I). J-L Pax $9{ }^{\triangle S H F} ; M s \times 1^{+/-}$neonates displayed a pre-axial digit duplication (red arrows; $\mathbf{J}$ ), a normal palate (K) and frequently mild arch artery defects such as cervical aortic arch (CAo) and abnormal external and internal left common carotid artery (eLC, iLC; L). Ao, aorta; AoA, aortic arch; CP, cleft palate; LCC/RCC, left/right common carotid artery; LSA/RSA, left/right subclavian artery. Scale bars: $1 \mathrm{~mm}$ 

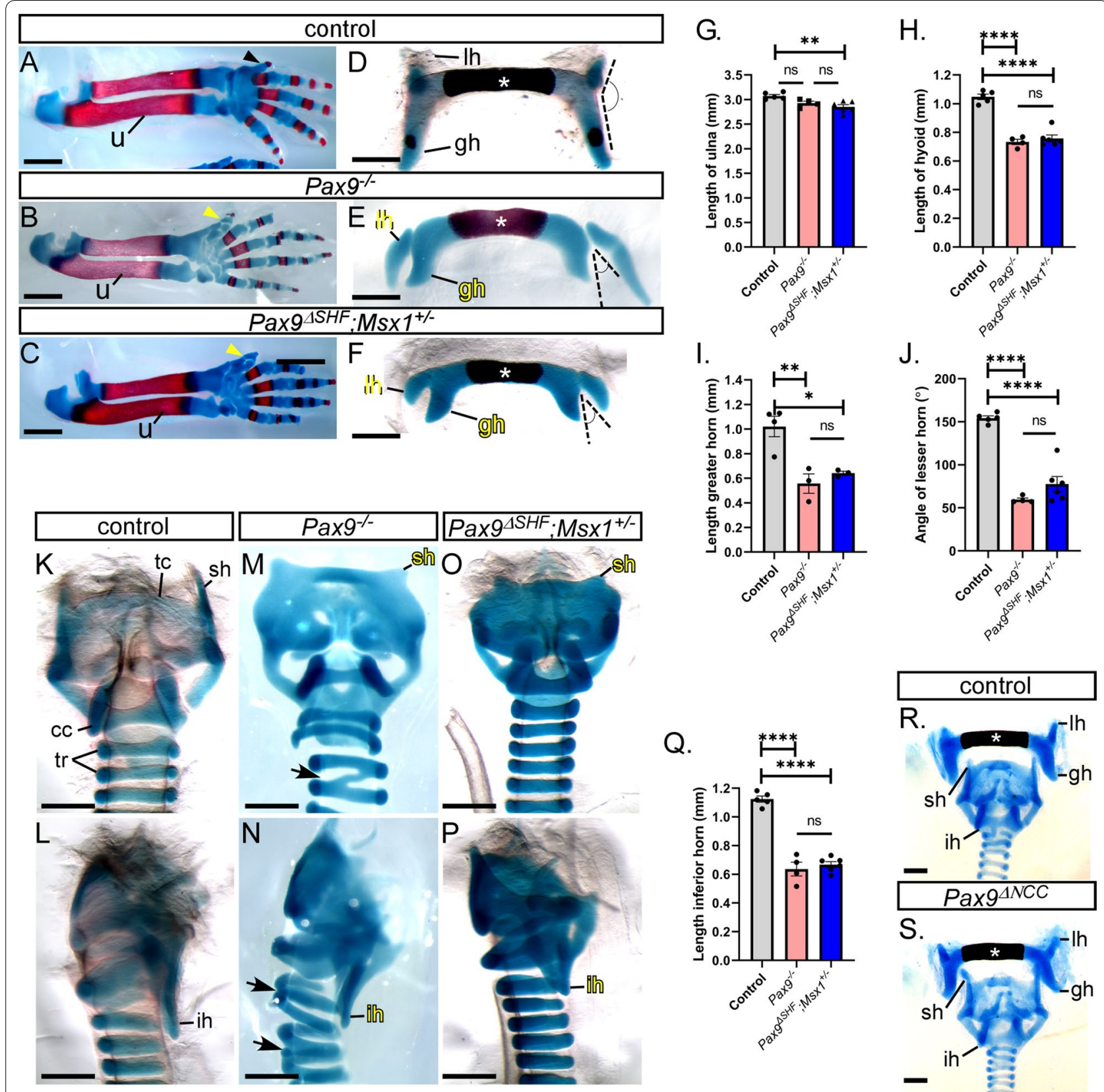

Fig. 7 Skeletal defects in Pax9 mutant mice on an enriched CD1 background. Neonate skeletons were stained for cartilage (blue) and bone (red). A-C Forelimbs in control neonates were normal (A), but a pre-axial digit duplication was present in $\mathrm{Pax} 9^{-/-}$(B) and Pax $9^{\Delta \mathrm{SHF}}$;Ms $\times 7^{+/-}(\mathbf{C})$ neonates (yellow arrowhead). D-F Skeletons were disarticulated to isolate the hyoid bone. G The ulna ( $u$ in $\mathbf{A}-\mathbf{C}$ ) of control $(n=5), P_{a x 9^{-/-}}$ $(n=4)$ and $\mathrm{Pax} 9^{\triangle S H F} ; M_{S X} 1^{+/-}(n=6)$ neonates was measured. There was a small yet significant reduction in the average length of the ulna in Pax ${ }^{\Delta S H F} ; M_{S x} 7^{+/-}$neonates. $\mathbf{H}-\mathbf{J}$ The ossification centre of the hyoid bone (asterisk in $\mathbf{D}-\mathbf{F}$ ), the length of the greater horn (gh) and the angle between the lesser (lh) and greater horns, were measured. K-P The tracheal rings (tr), thyroid (tc) and cricoid cartilages (cc) were examined. The

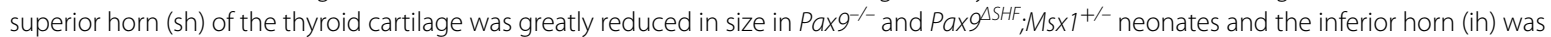
significantly reduced in length (Q). Fused tracheal rings were observed in Pax $9^{-/-}$neonates (arrows; M, N). R, S The hyoid and thyroid cartilage were normal in neonates with a conditional inactivation of Pax9 from neural crest cells ( $P a x Q^{\triangle N C C}$ ). One-way ANOVA with Tukey's multiple comparisons test. ns, not significant; ${ }^{* *} p<0.01,{ }^{* * * *} p<0.0001$. Scale bars: $1 \mathrm{~mm}$ in $\mathbf{A}-\mathbf{C}, 500 \mu \mathrm{m}$ in $\mathbf{E}-\mathbf{G}, \mathbf{J}-\mathbf{O}, \mathbf{R}, \mathbf{S}$ 
is able to rescue the OFT defects, but not the 4th PAA defects [43]. This indicates that there is a complex regulation in gene expression within the pharyngeal region that controls different aspects of cardiovascular development. Tbx1 is a DNA binding transcription factor that has many functions, including chromatin remodelling, histone modification and priming enhancers for downstream activation or repression [1, 44]. Tbx1 functionally interacts with $\operatorname{Pax} 9$ [3], which also has additional roles beyond being a transcription factor as a regulator of heterochromatin [45] and in ribosome production [46]. There are therefore multiple areas for targeting by background-specific modifiers that may affect cardiovascular defects caused by $\operatorname{Pax} 9$ deficiency.

Future studies could employ quantitative trait loci analysis to detect important chromosomal linkage markers to identify modifier regions that would explain the genetics underlying these phenotypic changes. Patients with heterozygous frameshifts, nonsense and missense mutations in PAX9 commonly present with non-syndromic hypodontia or oligodontia [47-51], but although reports of PAX9 deletions are infrequent, some do include heart defects [23-26]. This heterogeneity in phenotype presentation may be an example of genetic or environmental modifiers which have a detrimental effect on cardiovascular development.

During cardiovascular development the PAAs form symmetrically and rapidly remodel to become the asymmetric arch arteries seen in the adult. Specifically, the 3rd PAAs form the common carotids and the proximal part of the internal carotid arteries, and the 4th PAAs form the aortic arch on the left and the proximal part of the subclavian artery on the right $[52,53]$. The section of the paired dorsal aorta between the 3rd and 4th PAAs, the carotid duct, involutes and the dorsal aorta cranial to this becomes the distal internal carotid artery. In patients, failure of the 3rd PAAs to be maintained results in the absence of the common carotid arteries and the separate origins of the internal and external carotids [54], a phenotype seen in $\mathrm{PaxO}^{-/-}$mice [3]. This defect is often seen in conjunction with a cervical aortic arch [55] which is clinically rare but may be asymptomatic [56], and is associated with 22q11 Deletion Syndrome (DS) [57]. If the right 4th PAA does not form, an A-RSA is seen, which may be retro-esophageal or cervical in origin. RE-RSA is considered a variant as it is relatively common, seen in $\sim 1 \%$ of the population [58], but is more prevalent in Down syndrome [59] and may be asymptomatic or cause difficulties in swallowing [60]. In mice, heterozygous deletion of $T b x 1$, the gene associated with the cardiovascular defects in 22q11DS patients [42, 61, 62], predominantly affects development of the 4th PAAs and up to half of these mutants have RE-RSA but they are viable
[61]. If the left 4th PAA fails to form, however, this results in an IAA-B which is lethal once the arterial duct closes postnatally [60], and half of all cases of IAA-B are found in 22q11DS patients [63-65]. IAA-B is only observed in a minority of mice heterozygous for $T b x 1$ although when combined with $\operatorname{Pax} 9$ heterozygosity this increases considerably suggesting that $T b x 1$ and $\operatorname{Pax} 9$ functionally interact in 4th PAA morphogenesis [3]. $\mathrm{Pax}^{-/-}$mice display a high penetrance of IAA-B, but in $\operatorname{Pax}^{-/-} ; M s x 1^{+/-}$ mutants the incidence of this defect is significantly reduced and there is an increase in potentially non-lethal arch artery defects such as cervical origins of the aortic arch and right subclavian artery. These defects have been reported in a child with IAA in which the explanation for the patient's survival was the presence of these cervical vessels that allowed for a complete systemic circulation through the remodelled 3rd PAAs in combination with the persistence of the carotid ducts [66].

From our data it appears that Msx1 heterozygosity in Pax9-deficient mice enables the normal development of the left and right 4th PAAs in a proportion of mutants as shown by a significant reduction in the incidence of IAA and RE-RSA, respectively. Immunostaining for SMC, and counting NCC in the pharyngeal arches, at midembryogenesis upholds the idea that the 3rd PAAs are stabilised in $\operatorname{Pax}^{-/-} ; \mathrm{Msx}^{+/-}$mutants by NCC migration and differentiation into SMC to support the vessels as they morph into the common carotid arteries. This does not occur in mice deficient for $\operatorname{Pax} 9$ where the 3 rd PAAs collapse leading to absence of the common carotid arteries and an arterial duct-dependent defect [3]. We have confirmed here that $\operatorname{Pax} 9$ and $M s x 1$ have non-overlapping expression patterns in the pharyngeal arches at mid-embryogenesis, with $\operatorname{Pax} 9$ specifically expressed in the pharyngeal endoderm, and Msx 1 in NCC. Interestingly, it has recently been shown that Pax9 is expressed in adult aortic vascular SMC, and $\operatorname{Pax} 9$ siRNA knockdown in vitro inhibits their phenotypic transformation, proliferation and migration [67]. It is therefore possible, at least in adult aorta, that PAX9 may have a cell autonomous role in SMC. Ink injection data at E10.5, and $\mu \mathrm{CT}$ analysis at E12.5, confirms that the morphogenesis of fewer 3rd and 4th PAAs are affected in the $\operatorname{Pax}^{9^{-/-}} ; M s x 1^{+/-}$mutants compared to $\mathrm{Pax}^{-/-}$mice. It is well recognised, particularly in Tbx1-heterozygous mice, that the 4th PAAs have the capacity to recover from a hypoplastic vessel to a normal arch artery during development $[3,68,69]$. As a significantly higher proportion of hypoplastic 4th PAAs are seen in $\mathrm{PaxO}^{-/-} ; \mathrm{Msx1}^{+/-}$compared to $\mathrm{Pax}^{-/-}$mutants, this could lead to more normal aortic arches or right subclavian arteries being formed in later development. In the absence of 4th PAA derived aortic arch arteries, and in conjunction with a significantly increased proportion of 
intact 3rd PAAs in $\mathrm{Pax}^{-/-} ; \mathrm{Msx}^{+/-}$embryos, we propose that these remodel to form an aorta or right subclavian artery of cervical origin with persistent carotid ducts. In theory this phenotype should have been compatible with an intact systemic circulation and neonatal survival, but this was not the case. We therefore considered that the cleft palate seen in all neonates with a $\mathrm{Pax}^{-/-}$genotype may be causing the neonatal lethality as mutant mice with cleft palate die within $24 \mathrm{~h}$ of birth [10]. We used conditional inactivation of $\operatorname{Pax} 9$ in the SHF to engineer mutants which recapitulated the cardiovascular and limb defects of the $\operatorname{Pax} 9^{-/-}$mice but did not affect development of the palate. These mutants, nevertheless, did not survive long after birth despite the majority having a cardiovascular phenotype that could theoretically support a systemic circulation. Analysis of the neonatal skeletons, however, revealed defects of the hyoid bone and thyroid cartilage. The hyoid bone attaches to many muscles and ligaments associated with the floor of the mouth, as well as the larynx, pharynx, tongue, and epiglottis. The hyoid bone is necessary to maintain patency of the airway between the oropharynx and tracheal rings, and also functions in swallowing and breathing, as well as maintaining the posture of the head [70]. Given the importance of the hyoid bone in swallowing, malformation is a likely candidate for neonatal death, especially when considering the $\mathrm{Pax}^{-/-}$phenotype, which includes gasping respiration with redirection of air into the intestines, lack of suckling and presence of milk in the stomach, and the absence of a lung phenotype [4]. Also, it has been reported that muscle abnormalities produce a similar defect and the hyoid bone coordinates muscles involved in swallowing [10]. Additionally, fracture of the hyoid bone may severely compromise the upper airway [71]. Pax9 has been shown to functionally interact with $T b x 1$ in the pharyngeal endoderm [3] and mutant mice, in which $T b x 1$ was deleted specifically from NCC have a hyoid defect and die in the neonatal period with no remarkable craniofacial or other phenotypes that could explain death [72]. Interestingly, the neonates show the same absence of feeding as $\operatorname{Pax} 9$ mutants [4]. Furthermore, conditional deletion of Tbx1 with Twist2-Cre (described as being active in osteochondro-progenitors) produces a similar hyoid phenotype and the mutants die on the day of birth without feeding and without any other noticeable defects that could indicate another cause of death [72]. The shortened region of hyoid ossification seen in our study, however, is unlikely to be the cause of death as a similar phenotype is seen in Runx2 heterozygous mice, and these are viable [73]. The structural abnormalities seen in the horns of the hyoid and thyroid cartilage in $\operatorname{Pax} 9$ mutant mice are therefore more likely to be the cause of death through breathing and feeding difficulties, as well as vocalisations, all of which are detrimental to the survival of the neonate [10].

Pax9 is expressed in cranial NCC, and mutants with a conditional inactivation using the Wnt1Cre transgene develop a cleft palate but they do not have any cardiovascular abnormalities $[3,33]$. The lesser horns of the hyoid are derived from NCC populating the second pharyngeal arch, the greater horns and body of the hyoid are from the third, and throat cartilage from the fourth pharyngeal arch NCC [74, 75]. Here we now show that loss of Pax9 from NCC does not affect the hyoid bone or thyroid cartilage structures. It is therefore likely that the defects of these structures in $\mathrm{Pax}^{-/-}$and $\mathrm{Pax} 9^{\triangle S H F}$ mutants originate from loss of $\operatorname{Pax} 9$ expression in the endoderm. This could be analogous to $T b x 1$ inactivation from the pharyngeal endoderm which leads to aplasia of the tympanic ring, a structure derived from non-Tbx1 expressing mesenchyme [76]. Although the mechanism as to how this occurs has not been defined, it is feasible that a non-cell autonomous signalling event from the endoderm, involving $\operatorname{Pax} 9$, has been perturbed. It is known that signals from the endoderm regulate neural crest patterning [77, 78]. A mechanism such as this could explain why there is a reduction in the number of pharyngeal arch NCC and a loss of SMC supporting the remodelling 3rd PAAs in $\mathrm{Pax}^{-/-}$embryos [3]. An alternative explanation, however, is that a structural defect in the pharyngeal endoderm itself may be affecting NCC behaviour. The caudal pharyngeal arches of $\operatorname{Pax} 9^{-/}$embryos are smaller than in wild-type embryos $[3,4]$ suggesting that the structure of this tissue itself may play a role in the overall phenotype. Studies have implicated the chicken and zebrafish endoderm in exhibiting a signalling interaction with NCC to influence their morphogenetic potential in the formation of the hyoid [79, 80]. Furthermore, it has been shown that Fibroblast Growth Factor-dependent morphogenesis of the pharyngeal endoderm into pouches in zebrafish is critical for the later patterning of the hyoid cartilages [81].

The mechanism underlying the effect of $M s x 1$ heterozygosity on the $\mathrm{Pax} 9^{-/-}$phenotype still needs to be deduced but could be related to signalling processes between the $\operatorname{Pax} 9$-expressing endoderm and Msx1expressing NCC. The mechanism, however, appears to involve the rescue of NCC migration and differentiation to the smooth muscle cells that invest the remodelling third PAAs. This presumably stabilises the vessels enabling them to complete their morphogenesis into the common carotid arteries. Future work to uncover the genetic interactions controlling this process could examine the expression of key genes linked to $\operatorname{Pax} 9$ and $M s x 1$. Although $\operatorname{Pax} 9$ and $M s x 1$ have been shown to regulate Bmp4 in craniofacial development [16], and loss of Bmp4 
results in PAA defects [82] we did not detect any change in Bmp4 expression in $\mathrm{Pax}^{-/-}$pharyngeal arches at E9.5 in our published RNA-seq data [3]. This suggests that alternative interacting genes need to be investigated such as Notch ligands and their downstream effectors (e.g. Hes, Hey), which are also known to play crucial roles in cardiovascular development [83].

Furthermore, $\operatorname{Pax} 9^{-/-}$mice have a duplicated first digit [4], whereas Msx 1;Msx2 double null mutants either lack this digit or form an additional one [84]. In our $\mathrm{Pax}^{-/-}$ ;Ms $x 1^{-/-}$double knockout mutants the digits are normal, indicating that complete loss of $M s \times 1$ can further modulate the presentation of a phenotype in tissues other than those that form the cardiovascular system. All $\mathrm{Pax}^{-/-}$ and $\operatorname{Pax}^{-/-} ; \mathrm{Msx}^{+/-}$mutants have some form of aortic arch artery defect at the foetal and neonatal stages, but of the $\operatorname{Pax} 9^{-/-} ; M s x 1^{-/-}$double nulls examined five out of seven had normal cardiovascular development with no apparent defects of the heart or arch arteries. Although conclusions about PAA development at the younger stages are difficult to make because of the low numbers of mutants collected at E10.5 and E12.5, it does seem likely that a rescue of the $\mathrm{Pax}^{-/-}$cardiovascular phenotype through loss of both Msx 1 alleles has occurred. This, coupled with the absence of a limb phenotype in the double homozygous mutants, strongly suggests a complex regulation of gene expression controlled by $\operatorname{Pax} 9$ and $M s x 1$. Further experiments will be required to understand how these two genes are interacting in a gene regulatory network that is critical for embryonic development.

\section{Conclusions}

Mice deficient for $\operatorname{Pax} 9$ on a CD1 congenic background present with different cardiovascular defects when compared to mice congenic for $\mathrm{C} 57 \mathrm{Bl} / 6$. Although it is well known that genetically altered mice may present with different phenotypes depending on the genetic background they are bred or maintained on, this study demonstrates the need to establish the full phenotype on any new genetic background being used, particularly when making comparisons investigating interactions between two genes where the mouse strains may be different.

We have shown that $M s x 1$ haploinsufficiency in $\operatorname{Pax}^{-}$ ${ }^{\prime-}$ mice changes the arch artery phenotype through an unknown mechanism which involves the partial rescue of NCC migration to the 3rd pharyngeal arches and the stabilisation of the 3rd PAAs by investment with SMC. We propose that in the absence of 4th PAAs, the 3rd PAAs, with persistence of the carotid ducts, are able to remodel into an aortic arch or right subclavian artery of cervical origin theoretically compatible with a systemic blood circulation. Despite engineering this phenotype in mice, but without a cleft palate, neonatal death still occurred, and this was subsequently found to be possibly caused by defective hyoid bone and thyroid cartilage development via a putative Pax9 and/or endodermal non-cell autonomous signalling pathway.

\section{Materials and methods \\ Mice}

The mice used in this study have previously been described elsewhere: $\operatorname{Pax}^{+/-}$[4], $\operatorname{Pax} 9^{\text {flox }}$ [33], $\operatorname{Pax} 9^{\mathrm{Cre}}$ [3], (the Pax9 lines were created in our laboratories), $M s x 1^{+/-}$[12] (acquired from Richard Maas, Brigham Women's Hospital, Boston, MA, USA), Msx $1^{\text {Cre-ERT2 [31] }}$ (acquired from Benoit Robert, Institut Pasteur, Paris, France), Isl1Cre [32] (acquired from Sylvia Evans, University of California San Diego, CA, USA), Wnt1Cre [85] (acquired from Andrew McMahon, University of Southern California, CA, USA) and $R 26 R^{\text {lacZ }}$ [86], (purchased from The Jackson Laboratory, Bar Harbor, ME, USA). All mice were maintained on a congenic $\mathrm{CD} 1$ genetic background unless otherwise stated. All studies involving animals were performed in accordance with UK Home Office Animals (Scientific Procedures) Act 1986 and in compliance with the ARRIVE guidelines.

\section{Breeding}

Male and female mice were mated and the detection of a vaginal plug the next morning considered to be embryonic day (E) 0.5. Pregnant females were either culled on the required day and embryos collected or allowed to litter for collection of neonates. All mice used in the study were euthanised by cervical dislocation. Embryos at E9.5E11.5 were staged by somite counting. All mouse lines and embryos were genotyped by standard PCR (primer details given in Additional file 4: Table S3).

\section{Imaging}

Magnetic resonance imaging (MRI), micro-computed tomography $(\mu \mathrm{CT})$ and high resolution episcopic microscopy (HREM) techniques were performed as previously described [3, 87-90]. To visualise patency of pharyngeal arch arteries at E10.5, embryos were injected with India ink via the left ventricle with pulled Pasteur pipettes [3].

\section{Histology, X-Gal staining and Immunohistochemistry}

Whole embryos and neonate hearts were processed for histology and immunostaining analysis. Briefly, samples were fixed in $4 \%$ paraformaldehyde, dehydrated in ethanol and embedded in paraffin wax blocks for sectioning at $8 \mu \mathrm{m}$ thickness using a Leica RM 2235 microtome (Leica Biosystems, Milton Keynes, UK). For histology, slides were dewaxed, rehydrated, and stained with haematoxylin and eosin (ThermoFisher Scientific, Waltham, MA, USA) using a standard protocol, and mounted with 
histomount (National Diagnostics, Atlanta, GA, USA). $\mathrm{X}$-Gal staining to visualise lacZ expression at E10.5 was performed using standard techniques. To activate Cre expression in pregnant $M s \times 1^{C r e-E R T 2}$ mice, Tamoxifen (3 mg) was administered intraperitoneally at E9.5 as described [18]. For immunohistochemistry, slides with coronal sections of each embryo were dewaxed, rehydrated and immunostained with the primary antibodies shown in Additional file 4: Table S4. To assess an apoptotic index within the pharyngeal arches, control and mutant embryos at E9.5 and E10.5 ( $\mathrm{n}=3$ per genotype) were examined following immunostaining with the anticaspase 3 antibody. To assess a proliferative index within the pharyngeal arches, control and mutant embryos at E9.5 and E10.5 ( $\mathrm{n}=3$ per genotype) were examined following immunostaining with the anti-histone $\mathrm{H} 3$ antibody. Nuclei were stained with DAPI. Each pharyngeal arch examined was demarcated by the flanking pouch and cleft of the anterior and posterior arch, and cells from $n \geq 3$ sections per embryo were counted. All stained slides were viewed with a Zeiss Axioplan microscope equipped with Axiovision software (Carl Zeiss, Jena, Germany). The apoptotic or proliferative index was calculated by counting the number of positively stained cells divided by the total number of DAPI stained cells within each pharyngeal arch. To count neural crest cells, sections were immunostained using the anti-AP- $2 \alpha$ antibody and positively stained cells within each pharyngeal arch counted $(n=3$ per genotype; $n \geq 3$ sections per embryo). Cell counting was performed using ImageJ software (National Institutes of Health, Bethesda, MD, USA) using the cell counter feature.

\section{Bone and cartilage staining}

Bone and cartilage staining was performed on the skeletons of postnatal day 0 (P0) neonates found dead on the day of birth, or euthanised at P5 using $200 \mathrm{mg} / \mathrm{ml}$ of pentobarbital sodium solution (Euthatal; Boehringer Ingelheim Animal Health UK Limited, Bracknell, UK). Neonates were incubated at $70^{\circ} \mathrm{C}$ for $30 \mathrm{~s}$, the skin peeled away and eviscerated, fixed in $95 \%$ ethanol overnight at room temperature and then transferred to acetone at room temperature for $48 \mathrm{~h}$ to remove the fat. The neonates were then rinsed in water and incubated in $0.01 \%$ alcian blue solution (Merck Life Science UK Limited, Gillingham, UK) for 8 days to stain the cartilage. The neonates were washed with $70 \%$ ethanol and incubated in $1 \%$ potassium hydroxide solution until the tissue was visibly cleared. Staining of bone was performed with $0.001 \%$ alizarin red solution (Merck Life Science UK Limited) and the tissue further cleared in a $1 \%$ potassium hydroxide $/ 20 \%$ glycerol solution, increasing to $100 \%$ glycerol. Skeletons were examined and images captured using a
Leica MZ6 stereomicroscope with a Leica DFC295 camera and the Leica Application Suite software, version 3 (Leica Microsystems UK Ltd, Milton Keynes, UK).

\section{Single cell mRNA sequencing}

The caudal pharyngeal arch region was dissected from four E9.5 embryos and the tissue dissociated to single cells using Accumax (ThermoFisher Scientific) by incubating at $37{ }^{\circ} \mathrm{C}$ for $30 \mathrm{~min}$. The reaction was stopped by the addition of $10 \%$ fetal calf serum (FCS), and cells were washed in PBS and resuspended in 10\% FCS. Fluorescence-activated cell sorting was performed on a Becton Dickinson FACS Aria II using a $100 \mu \mathrm{m}$ nozzle and a sheath pressure of 20 psi. Single cells were gated using FSC-A versus SSC-A followed by FSC-A versus FSC-H and FSC-A versus SSC-W to remove any doublets. Live single cells were gated using propidium iodide versus FSC-A, and this population was sorted into collection tubes. Single cells were loaded onto the C1 Single-Cell mRNA-Seq HT IFC [10-17 $\mu \mathrm{m}$ ] (Fluidigm, San Francisco, CA, USA). Cell lysis, reverse transcription and cDNA amplification were performed using the SMARTSeq v4 Ultra Low Input RNA Kit for the Fluidigm C1 System (Takara Bio USA, Inc, Mountain View, CA, USA). Libraries were pooled and sequenced $(2 \times 75 \mathrm{bp})$ on the Ilumina NextSeq 500. Reads were trimmed for quality with Trimmomatic (version 0.33) giving an average of 1,756,297 reads per cell (range 1,057,053-3,185,503). Reads were aligned to the mouse reference genome (GRCm38.p5, version M16) and Ambion spike sequences (1, 4 and 7) using STAR (version 2.4.0j). An average of $1,437,448$ reads were uniquely mapped (range 226,060$2,742,686$ ). Reads were quantified using HTSEQ (version 0.6.1) and a count matrix created for analysis (Additional file 5: Table S1).

\section{Statistical analysis}

Fisher's exact test was used to compare defect frequencies between different genotypes using IBM SPSS Statistics for Windows (Version 25.0; IBM Corp., Armonk, NY, USA). Cell counts were analysed using a one-way ANOVA with Tukey's multiple comparisons test (Prism 8.01, GraphPad Software, San Diego, CA, USA). Groups were considered significantly different when $p<0.05$.

\section{Abbreviations}

AD: Arterial duct; Ao: Aorta; ANOVA: Analysis of variance; CAo: Cervical aortic arch; A-RSA: Aberrant right subclavian artery; BC: Brachiocephalic artery; Bmp4: Bone morphogenetic protein 4; CC: Common carotid artery; CP: Cleft palate; CRSA: Cervical right subclavian artery; dAo: Dorsal aorta; DORV: Double outlet right ventricle; E: Embryonic day; eLC: External left carotid artery; eRC: External right carotid artery; GH: Greater horn (of hyoid); HREM: High resolution episcopic microscopy; IAA: Interrupted aortic arch; IAA-B: Interrupted aortic arch, type B; IH: Inferior horn (of thyroid cartilage); iLC: Internal left carotid artery; iRC: Internal right carotid artery; IsI1: Islet 1; IVC: Interventricular 
communication; LCC: Left common carotid artery; LH: Lesser horn (of hyoid); LSA: Left subclavian artery; LV: Left ventricle; MRI: Magnetic resonance imaging; Msx 1: Muscle segment homeobox 1; RCC: Right common carotid artery; RE-RSA: Retro-esophageal right subclavian artery; RSA: Right subclavian artery; RV: Right ventricle; NCC: Neural crest cell; P: Palate; PA: Pharyngeal arch; PAA: Pharyngeal arch artery; Pax9: Paired box 9; PSC: Primitive subclavian complex PT: Pulmonary trunk; Runx2: Runt-related transcription factor 2; SHF: Second heart field; SH: Superior horn (of thyroid cartilage); SMC: Smooth muscle cells; Tbx1: T-box transcription factor 1;Th: Thymus; U: Ulna; VSD: Ventricular septal defect; Wnt1: Wingless-type MMTV integration site family, member 1.

\section{Supplementary Information}

The online version contains supplementary material available at https://doi. org/10.1186/s12861-021-00245-5.

Additional file 1. Caudal PAA defects in CD1-Pax $9^{-/-}$and

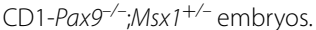

Additional file 2. Defects in $\mathrm{Pax}^{-/-} ;{\mathrm{Ms} \times 1^{-/-}}^{-}$embryos on a congenic CD1 genetic background.

Additional file 3. Apoptosis and cell proliferation are not affected in $\mathrm{Pax}^{-}$ ${ }^{-}$and $\mathrm{Pax}^{-/-} ; \mathrm{MSX}^{+1 /-}$ mutant embryos on a congenic $\mathrm{CD} 1$ background.

Additional file 4. Additional Tables S2-4.

Additional file 5. Additional Table S1. Count matrix of reads in 86 single cells from the caudal pharyngeal arches of E9.5 mouse embryos.

\section{Acknowledgements}

The authors would like to thank former lab members for their support in this study, particularly Silvia Mazzotta, Catherine Stothard, Alberto Briones-Leon and Kathleen Allinson. We thank the Newcastle University Flow Cytometry Core Facility for their assistance.

\section{Authors' contributions}

RRK performed experiments, analysed data and acquired funding for a PhD Studentship. RK, HP and HMP provided resources (mouse strains, antibodies), supervised the project and edited the manuscript. $\mathrm{RH}$ and JC generated the single cell transcriptome data. RQ analysed the single cell transcriptome data. JES provided imaging data for MRI and $\mu \mathrm{CT}$ analysis. TJM provided imaging data for HREM analysis. SZ generated the MsX1:lacZ lineage tracing embryo data. SDB designed and supervised the project, acquired funding, analysed the data, created the figures and wrote the manuscript. All authors read and approved the final manuscript.

\section{Funding}

This study was funded by a British Heart Foundation project grant (PG/16/39/32115; to S.D.B.), a Newcastle University Single Cell Unit Award (to S.D.B.) and a PhD Scholarship from Yarmouk University, Jordan (to R.R.K.). J.E.S. would like to acknowledge infrastructure funding from the British Heart Foundation, UK (SI/14/1/30718). This study was designed, performed, and the data analysed and interpreted by the authors. The funding sources provided financial support for the experiments described.

\section{Availability of data and materials}

The MRI, HREM and $\mu \mathrm{CT}$ imaging datasets analysed during the current study are openly available at https://doi.org/10.25405/data.ncl.c.5431437.v1.

\section{Declarations}

\section{Ethics approval and consent to participate}

Mice were used in accordance with the permissions on our project licence P0CD9CAB6 obtained from the UK Home Office under the revised Animals (Scientific Procedures) Act 1986, and the study was carried out in compliance with the ARRIVE guidelines. All experimental protocols were approved by the Animal Welfare and Ethical Review Body at Newcastle University. Written informed consent was obtained from the owners of the animals to use in our study.

\section{Consent for publication}

Not applicable.

\section{Competing interests}

The authors declare that they have no competing interests.

\section{Author details}

${ }^{1}$ Newcastle University Biosciences Institute, Centre for Life, Newcastle NE1 3BZ, UK. ${ }^{2}$ School of Dental Sciences, Newcastle University, Newcastle NE2 4BW, UK. ${ }^{3}$ Bioinformatics Support Unit, Newcastle University, Newcastle NE1 3BZ, UK. ${ }^{4}$ Genomics Core Facility, Newcastle University, Newcastle NE1 3BZ, UK. ${ }^{5}$ Biomedical Imaging, University of Leeds, Leeds LS2 9JT, UK. ${ }^{6}$ The Francis Crick Institute, London NW1 1AT, UK. ${ }^{7}$ INSERM, Marseille Medical Genetics, U1251, Aix Marseille University, Marseille, France. ${ }^{8}$ Present Address: Department of Basic Medical Sciences, Faculty of Medicine, Yarmouk University, Irbid, Jordan.

Received: 12 May 2021 Accepted: 23 September 2021

Published online: 06 October 2021

\section{References}

1. Baldini A, Fulcoli FG, Illingworth E. Tbx1: transcriptional and developmental functions. Curr Top Dev Biol. 2017;122:223-43.

2. Stothard CA, Mazzotta S, Vyas A, Schneider JE, Mohun TJ, Henderson DJ, Phillips HM, Bamforth SD. Pax9 and Gbx2 interact in the pharyngeal endoderm to control cardiovascular development. J Cardiovasc Dev Dis. 2020;7(2):20.

3. Phillips HM, Stothard CA, Shaikh Qureshi WM, Kousa Al, Briones-Leon JA, Khasawneh RR, O'Loughlin C, Sanders R, Mazzotta S, Dodds R, et al. Pax9 is required for cardiovascular development and interacts with Tbx 1 in the pharyngeal endoderm to control 4th pharyngeal arch artery morphogenesis. Development. 2019;146(18):93.

4. Peters H, Neubuser A, Kratochwil K, Balling R. Pax9-deficient mice lack pharyngeal pouch derivatives and teeth and exhibit craniofacial and limb abnormalities. Genes Dev. 1998;12(17):2735-47.

5. Kist R, Watson M, Crosier M, Robinson M, Fuchs J, Reichelt J, Peters H. The formation of endoderm-derived taste sensory organs requires a Pax9dependent expansion of embryonic taste bud progenitor cells. PLoS Genet. 2014;10(10):e1004709.

6. Neubuser A, Koseki H, Balling R. Characterization and developmental expression of Pax9, a paired-box-containing gene related to Pax1. Dev Biol. 1995:170(2):701-16.

7. Peters H, Wilm B, Sakai N, Imai K, Maas R, Balling R. Pax1 and Pax9 synergistically regulate vertebral column development. Development. 1999;126(23):5399-408.

8. Dixon MJ, Marazita ML, Beaty TH, Murray JC. Cleft lip and palate: understanding genetic and environmental influences. Nat Rev Genet. 2011;12(3):167-78.

9. Kasatwar A, Borle R, Bhola N, Rajanikanth K, Prasad GSV, Jadhav A. Prevalence of congenital cardiac anomalies in patients with cleft lip and palate-its implications in surgical management. J Oral Biol Craniofac Res. 2017;8(3):241-4.

10. Turgeon B, Meloche S. Interpreting neonatal lethal phenotypes in mouse mutants: insights into gene function and human diseases. Physiol Rev. 2009;89(1):1-26.

11. Phillips PC. Epistasis - the essential role of gene interactions in the structure and evolution of genetic systems. Nat Rev Genet. 2008:9(11):855-67.

12. Satokata I, Maas R. Msx 1 deficient mice exhibit cleft palate and abnormalities of craniofacial and tooth development. Nat Genet. 1994;6(4):348-56.

13. Ogawa T, Kapadia H, Wang B, D'Souza RN. Studies on Pax9-Msx1 protein interactions. Arch Oral Biol. 2005;50(2):141-5.

14. Nakatomi M, Wang X-P, Key D, Lund JJ, Turbe-Doan A, Kist R, Aw A, Chen Y, Maas RL, Peters H. Genetic interactions between Pax9 and Msx 1 regulate lip development and several stages of tooth morphogenesis. Dev Biol. 2010;340(2):438-49

15. Nakatomi M, Ludwig KU, Knapp M, Kist R, Lisgo S, Ohshima H, Mangold E, Peters H. Msx1 deficiency interacts with hypoxia and induces a morphogenetic regulation during mouse lip development. Development. 2020;147(21):dev189175. 
16. Ogawa T, Kapadia H, Feng JQ, Raghow R, Peters H, D'Souza RN. Functional consequences of interactions between Pax9 and Msx1 genes in normal and abnormal tooth development. J Biol Chem. 2006;281 (27):18363-9.

17. Goupille O, Saint Cloment C, Lopes M, Montarras D, Robert B. Msx1 and Msx2 are expressed in sub-populations of vascular smooth muscle cells. Dev Dyn. 2008;237(8):2187-94.

18. Papoutsi T, Odelin G, Moore-Morris T, Puceat M, de la Pompa JL, Robert B, Zaffran S. Msx1 (cre) (ERT) (2) knock-In allele: a useful tool to target embryonic and adult cardiac valves. Genesis. 2015:53(5):337-45.

19. Chen YH, Ishii M, Sun J, Sucov HM, Maxson RE Jr. Msx1 and Msx2 regulate survival of secondary heart field precursors and post-migratory proliferation of cardiac neural crest in the outflow tract. Dev Biol. 2007;308(2):421-37.

20. Chen YH, Ishii M, Sucov HM, Maxson RE Jr. Msx1 and Msx2 are required for endothelial-mesenchymal transformation of the atrioventricular cushions and patterning of the atrioventricular myocardium. BMC Dev Biol. 2008;8:75.

21. Cordell HJ, Bentham J, Topf A, Zelenika D, Heath S, Mamasoula C, Cosgrove C, Blue G, Granados-Riveron J, Setchfield K, et al. Genome-wide association study of multiple congenital heart disease phenotypes identifies a susceptibility locus for atrial septal defect at chromosome 4p16. Nat Genet. 2013:45(7):822-4.

22. Lahm H, Jia M, Dressen M, Wirth F, Puluca N, Gilsbach R, Keavney BD, Cleuziou J, Beck N, Bondareva O, et al. Congenital heart disease risk loci identified by genome-wide association study in European patients. J Clin Invest. 2021;131(2):e141837.

23. Santen GW, Sun Y, Gijsbers AC, Carre A, Holvoet M, Haeringen A, Lesnik Oberstein SA, Tomoda A, Mabe H, Polak M, et al. Further delineation of the phenotype of chromosome 14q13 deletions: (positional) involvement of FOXG1 appears the main determinant of phenotype severity, with no evidence for a holoprosencephaly locus. J Med Genet. 2012;49(6):366-72.

24. Schuffenhauer S, Leifheit $\mathrm{H}-\mathrm{J}$, Lichtner P, Peters H, Murken J, Emmerich P. De novo deletion (14)(q11.2q13) including PAX9: clinical and molecular findings. J Med Genet. 1999:36(3):233-6.

25. Shapira SK, Anderson KL, Orr-Urtregar A, Craigen WJ, Lupski JR, Shaffer LG De novo proximal interstitial deletions of 14q: cytogenetic and molecular investigations. Am J Med Genet. 1994;52(1):44-50.

26. Hayashi S, Yagi M, Morisaki I, Inazawa J. Identical deletion at 14q13.3 including PAX9 and NKX2-1 in siblings from mosaicism of unaffected parent. J Hum Genet. 2015;60:203-6.

27. Doetschman T. Influence of genetic background on genetically engineered mouse phenotypes. Methods Mol Biol. 2009;530:423-33.

28. Johnson AL, Schneider JE, Mohun TJ, Williams T, Bhattacharya S, Henderson DJ, Phillips HM, Bamforth SD. Early embryonic expression of AP-2a is critical for cardiovascular development. J Cardiovasc Dev Dis. 2020;7(3):27.

29. Bamforth SD, Braganca J, Farthing CR, Schneider JE, Broadbent C, Michell AC, Clarke K, Neubauer S, Norris D, Brown NA, et al. Cited2 controls left-right patterning and heart development through a Nodal-Pitx2C pathway. Nat Genet. 2004;36(11):1189-96.

30. Houzelstein D, Cohen A, Buckingham ME, Robert B. Insertional mutation of the mouse Msx1 homeobox gene by an nlacZ reporter gene. Mech Dev. 1997;65(1-2):123-33.

31. Lallemand Y, Moreau J, Cloment CS, Vives FL, Robert B. Generation and characterization of a tamoxifen inducible Msx1 (CreERT2) knock-in allele. Genesis. 2013;51(2):110-9.

32. Yang L, Cai CL, Lin L, Qyang Y, Chung C, Monteiro RM, Mummery CL, Fishman Gl, Cogen A, Evans S. Isl1 Cre reveals a common Bmp pathway in heart and limb development. Development. 2006;133(8):1575-85.

33. Kist $R$, Greally E, Peters H. Derivation of a mouse model for conditional inactivation of Pax9. Genesis. 2007:45(7):460-4.

34. Bensoussan-Trigano V, Lallemand Y, Saint Cloment C, Robert B. MsX1 and Msx2 in limb mesenchyme modulate digit number and identity. Dev Dyn. 2011;240(5):1190-202.

35. Engleka KA, Manderfield LJ, Brust RD, Li L, Cohen A, Dymecki SM, Epstein JA. Islet1 derivatives in the heart are of both neural crest and second heart field origin. Circ Res. 2012;110(7):922-6.

36. Noordzij JP, Ossoff RH. Anatomy and physiology of the larynx. Otolaryngol Clin North Am. 2006;39(1):1-10.
37. Minoux M, Antonarakis GS, Kmita M, Duboule D, Rijli FM. Rostral and caudal pharyngeal arches share a common neural crest ground pattern. Development. 2009;136(4):637-45.

38. Tabler JM, Rigney MM, Berman GJ, Gopalakrishnan S, Heude E, Al-Lami HA, Yannakoudakis BZ, Fitch RD, Carter C, Vokes S, et al. Cilia-mediated Hedgehog signaling controls form and function in the mammalian larynx. Elife. 2017:6:e19153.

39. Bamforth SD, Braganca J, Eloranta JJ, Murdoch JN, Marques FI, Kranc KR, Farza H, Henderson DJ, Hurst HC, Bhattacharya S. Cardiac malformations, adrenal agenesis, neural crest defects and exencephaly in mice lacking Cited2, a new Tfap2 co-activator. Nat Genet. 2001;29(4):469-74.

40. Hasten E, Morrow BE. Tbx1 and Foxi3 genetically interact in the pharyngeal pouch endoderm in a mouse model for 22q11.2 deletion syndrome. PLOS Genet. 2019;15(8):e1008301.

41. Kelly RG. Advances in the second heart field. Springer; 2020. p. 301-7.

42. Jerome LA, Papaioannou VE. DiGeorge syndrome phenotype in mice mutant for the T-box gene, Tbx1. Nat Genet. 2001;27(3):286-91.

43. Zhang Z, Huynh T, Baldini A. Mesodermal expression of Tbx 1 is necessary and sufficient for pharyngeal arch and cardiac outflow tract development. Development. 2006:133(18):3587-95.

44. Fulcoli FG, Franzese M, Liu X, Zhang Z, Angelini C, Baldini A. Rebalancing gene haploinsufficiency in vivo by targeting chromatin. Nat Commun. 2016;7:11688

45. Bulut-Karslioglu A, Perrera V, Scaranaro M, de la Rosa-Velazquez IA, van de Nobelen S, Shukeir N, Popow J, Gerle B, Opravil S, Pagani M, et al. A transcription factor-based mechanism for mouse heterochromatin formation. Nat Struct Mol Biol. 2012:19(10):1023-30.

46. Farley-Barnes KI, Deniz E, Overton MM, Khokha MK, Baserga SJ. Paired Box 9 (PAX9), the RNA polymerase II transcription factor, regulates human ribosome biogenesis and craniofacial development. PLoS Genet. 2020;16(8):e1008967.

47. Das P, Hai M, Elcock C, Leal SM, Brown DT, Brook AH, Patel PI. Novel missense mutations and a 288-bp exonic insertion in PAX9 in families with autosomal dominant hypodontia. Am J Med Genet A. 2003;118A(1):35-42.

48. Das P, Stockton DW, Bauer C, Shaffer LG, D'Souza RN, Wright T, Patel PI. Haploinsufficiency of PAX9 is associated with autosomal dominant hypodontia. Hum Genet. 2002:110(4):371-6.

49. Kapadia H, Frazier-Bowers S, Ogawa T, D'Souza RN. Molecular characterization of a novel PAX9 missense mutation causing posterior tooth agenesis. Eur J Hum Genet. 2006;14(4):403-9.

50. Nieminen P, Arte S, Tanner D, Paulin L, Alaluusua S, Thesleff I, Pirinen S. Identification of a nonsense mutation in the PAX9 gene in molar oligodontia. Eur J Hum Genet. 2001;9(10):743-6.

51. Stockton DW, Das P, Goldenberg M, D'Souza RN, Patel PI. Mutation of PAX9 is associated with oligodontia. Nat Genet. 2000;24(1):18-9.

52. Hiruma T, Nakajima Y, Nakamura H. Development of pharyngeal arch arteries in early mouse embryo. J Anat. 2002;201 (1):15-29.

53. Bamforth SD, Chaudhry B, Bennett M, Wilson R, Mohun TJ, Van Mierop $\mathrm{LH}$, Henderson DJ, Anderson RH. Clarification of the identity of the mammalian fifth pharyngeal arch artery. Clin Anat. 2013;26(2):173-82.

54. Roberts LK, Gerald B. Absence of both common carotid arteries. Am J Roentgenol. 1978:130(5):981-2

55. Bryan RN, Drewyer RG, Gee W. Separate origins of the left internal and external carotid arteries from the aorta. Am J Roentgenol. 1978;130(2):362-5.

56. Moncada R, Shannon M, Miller R, White H, Friedman J, Shuford WH. The cervical aortic arch. Am J Roentgenol Radium Ther Nucl Med. 1975;125(3):591-601

57. Unolt M, Versacci P, Anaclerio S, Lambiase C, Calcagni G, Trezzi M, Carotti A, Crowley TB, Zackai EH, Goldmuntz E, et al. Congenital heart diseases and cardiovascular abnormalities in 22q11.2 deletion syndrome: from well-established knowledge to new frontiers. Am J Med Genet Part A. 2018:176(10):2087-98.

58. Polednak AP. Prevalence of the aberrant right subclavian artery reported in a published systematic review of cadaveric studies: the impact of an outlier. Clin Anat. 2017;30(8):1024-8.

59. Scala C, Leone Roberti Maggiore U, Candiani M, Venturini PL, Ferrero $\mathrm{S}$, Greco T, Cavoretto P. Aberrant right subclavian artery in fetuses with Down syndrome: a systematic review and meta-analysis. Ultrasound Obstet Gynecol. 2015;46(3):266-76. 
60. Hanneman K, Newman B, Chan F. Congenital variants and anomalies of the aortic arch. Radiographics. 2017;37(1):32-51.

61. Lindsay EA, Vitelli F, Su H, Morishima M, Huynh T, Pramparo T, Jurecic V, Ogunrinu G, Sutherland HF, Scambler PJ, et al. Tbx1 haploinsufficieny in the DiGeorge syndrome region causes aortic arch defects in mice. Nature. 2001:410(6824):97-101.

62. Merscher S, Funke B, Epstein JA, Heyer J, Puech A, Lu MM, Xavier RJ, Demay MB, Russell RG, Factor $S$, et al. TBX1 is responsible for cardiovascular defects in velo-cardio-facial/DiGeorge syndrome. Cell. 2001;104(4):619-29.

63. Lewin MB, Lindsay EA, Jurecic V, Goytia V, Towbin JA, Baldini A. A genetic etiology for interruption of the aortic arch type B. Am J Cardiol. 1997:80(4):493-7.

64. Van Mierop LHS, Kutsche LM. Cardiovascular anomalies in digeorge syndrome and importance of neural crest as a possible pathogenetic factor. Am J Cardiol. 1986;58(1):133-7.

65. Boudjemline Y, Fermont L, Le Bidois J, Lyonnet S, Sidi D, Bonnet D. Prevalence of 22q11 deletion in fetuses with conotruncal cardiac defects: a 6-year prospective study. J Pediatr. 2001;138(4):520-4.

66. Suntratonpipat S, Bamforth SD, Johnson AL, Noga M, Anderson RH, Smallhorn J, Tham E. Childhood presentation of interrupted aortic arch with persistent carotid ducts. World J Pediatr Congenit Heart Surg. 2015;6(2):335-8

67. Xu J, Zhang Y, You S, Guo Y, Chen S, Chang Y, Zhang N, Sun Y. Paired box 9 regulates VSMC phenotypic transformation, proliferation, and migration via sonic hedgehog. Life Sci. 2020;257:118053.

68. Ryckebusch L, Bertrand N, Mesbah K, Bajolle F, Niederreither K, Kelly RG, Zaffran S. Decreased levels of embryonic retinoic acid synthesis accelerate recovery from arterial growth delay in a mouse model of DiGeorge syndrome. Circ Res. 2010;106(4):686-94.

69. Lindsay EA, Baldini A. Recovery from arterial growth delay reduces penetrance of cardiovascular defects in mice deleted for the DiGeorge syndrome region. Hum Mol Genet. 2001;10(9):997-1002.

70. Auvenshine RC, Pettit NJ. The hyoid bone: an overview. Cranio. 2020;38(1):6-14

71. Szeremeta W, Morovati SS. Isolated hyoid bone fracture: a case report and review of the literature. J Trauma. 1991;31 (2):268-71.

72. Funato N, Nakamura M, Richardson JA, Srivastava D, Yanagisawa H. Loss of Tbx1 induces bone phenotypes similar to cleidocranial dysplasia. Hum Mol Genet. 2015;24(2):424-35.

73. Otto F, Thornell AP, Crompton T, Denzel A, Gilmour KC, Rosewell IR, Stamp GW, Beddington RS, Mundlos S, Olsen BR, et al. Cbfa1, a candidate gene for cleidocranial dysplasia syndrome, is essential for osteoblast differentiation and bone development. Cell. 1997;89(5):765-71.

74. Santagati F, Minoux M, Ren SY, Rijli FM. Temporal requirement of Hoxa2 in cranial neural crest skeletal morphogenesis. Development. 2005;132(22):4927-36.

75. Chojnowski JL, Trau HA, Masuda K, Manley NR. Temporal and spatial requirements for Hoxa3 in mouse embryonic development. Dev Biol. 2016;415(1):33-45.
76. Arnold JS, Werling U, Braunstein EM, Liao J, Nowotschin S, Edelmann W, Hebert JM, Morrow BE. Inactivation of Tbx1 in the pharyngeal endoderm results in 22q11DS malformations. Development. 2006;133(5):977-87.

77. Couly G, Creuzet S, Bennaceur S, Vincent C, Le Douarin NM. Interactions between Hox-negative cephalic neural crest cells and the foregut endoderm in patterning the facial skeleton in the vertebrate head. Development. 2002;129(4):1061-73.

78. Graham A, Okabe M, Quinlan R. The role of the endoderm in the development and evolution of the pharyngeal arches. J Anat. 2005:207(5):479-87.

79. Ruhin B, Creuzet S, Vincent C, Benouaiche L, Le Douarin NM, Couly G. Patterning of the hyoid cartilage depends upon signals arising from the ventral foregut endoderm. Dev Dyn. 2003;228(2):239-46.

80. Crump JG, Swartz ME, Kimmel CB. An integrin-dependent role of pouch endoderm in hyoid cartilage development. PLoS Biol. 2004;2(9):E244.

81. Crump JG, Maves L, Lawson ND, Weinstein BM, Kimmel CB. An essential role for Fgfs in endodermal pouch formation influences later craniofacial skeletal patterning. Development. 2004;131(22):5703-16.

82. Liu W, Selever J, Wang D, Lu MF, Moses KA, Schwartz RJ, Martin JF. Bmp4 signaling is required for outflow-tract septation and branchial-arch artery remodeling. Proc Natl Acad Sci USA. 2004:101(13):4489-94.

83. High FA, Jain R, Stoller JZ, Antonucci NB, Lu MM, Loomes KM, Kaestner KH, Pear WS, Epstein JA. Murine Jagged1/Notch signaling in the second heart field orchestrates Fgf8 expression and tissue-tissue interactions during outflow tract development. J Clin Investig. 2009;119(7):1986-96.

84. Lallemand Y, Nicola MA, Ramos C, Bach A, Cloment CS, Robert B. Analysis of Msx1; Msx2 double mutants reveals multiple roles for Msx genes in limb development. Development. 2005:132(13):3003-14.

85. Danielian PS, Muccino D, Rowitch DH, Michael SK, McMahon AP. Modification of gene activity in mouse embryos in utero by a tamoxifeninducible form of Cre recombinase. Curr Biol. 1998;8(24):1323-6.

86. Soriano P. Generalized lacZ expression with the ROSA26 Cre reporter strain. Nat Genet. 1999;21(1):70-1.

87. Degenhardt K, Wright AC, Horng D, Padmanabhan A, Epstein JA. Rapid 3D phenotyping of cardiovascular development in mouse embryos by micro-CT with iodine staining. Circ Cardiovasc Imaging. 2010;3(3):314-22.

88. Bamforth SD, Schneider JE, Bhattacharya S. High-throughput analysis of mouse embryos by magnetic resonance imaging. Cold Spring Harb Protoc. 2012;2012(1):93-101.

89. Schneider JE, Bose J, Bamforth SD, Gruber AD, Broadbent C, Clarke K, Neubauer S, Lengeling A, Bhattacharya S. Identification of cardiac malformations in mice lacking Ptdsr using a novel high-throughput magnetic resonance imaging technique. BMC Dev Biol. 2004:4(1):16.

90. Weninger WJ, Geyer SH, Martineau A, Galli A, Adams DJ, Wilson R, Mohun TJ. Phenotyping structural abnormalities in mouse embryos using highresolution episcopic microscopy. Dis Model Mech. 2014;7(10):1143-52.

\section{Publisher's Note}

Springer Nature remains neutral with regard to jurisdictional claims in published maps and institutional affiliations.
Ready to submit your research? Choose BMC and benefit from:

- fast, convenient online submission

- thorough peer review by experienced researchers in your field

- rapid publication on acceptance

- support for research data, including large and complex data types

- gold Open Access which fosters wider collaboration and increased citations

- maximum visibility for your research: over 100M website views per year

At BMC, research is always in progress.

Learn more biomedcentral.com/submissions 